\title{
O gênero Chinavia Orian (Hemiptera, Pentatomidae, Pentatominae) no Brasil, com chave pictórica para os adultos ${ }^{1}$
}

\author{
Cristiano Feldens Schwertner ${ }^{2,3}$ \& Jocélia Grazia ${ }^{2,4}$
}

${ }^{1}$ Contribuição n. 532 do Departamento de Zoologia/UFRGS.

${ }^{2}$ Laboratório de Entomologia Sistemática, Departamento de Zoologia, Universidade Federal do Rio Grande do Sul, Av. Bento Gonçalves 9.500, Bloco IV, Prédio 43435, 91501-970, Porto Alegre-RS, Brasil.

${ }^{3}$ PPG Biologia Animal, bolsista PRODOC/CAPES, acrosternum@yahoo.com.br.

${ }^{4}$ Bolsista CNPq, jocelia@ufrgs.br.

\begin{abstract}
The genus Chinavia Orian (Hemiptera, Pentatomidae) in Brazil, with a pictorial key to adults. Chinavia Orian is one of the most speciose Pentatominae genera and is distributed in the Afrotropical, Nearctic and Neotropical regions. In Brazil, 32 species are recordered, from which 18 are endemic; host-plant association from 18 species are known, and immatures or some life history traits for six species were already described. In this work, we provided a diagnosis and discuss data available on immatures and biology of all species of Chinavia found in Brazil, including a pictorial key to adult identification. Two new synonyms are recognized: Acrosternum (Chinavia) bellum Rolston, 1983 is a junior synonym of Chinavia nigrodorsata (Breddin, 1903), and Acrosternum (Chinavia) panizzii Frey-da-Silva \& Grazia, 2001 is a junior synonym of Chinavia obstinata (Stål, 1860). Chinavia nigritarsis (Stål, 1872), formerly a synonym of Chinavia gravis (Walker, 1867), is reinstated. Color habitus ilustrations of all species are provided, the majority taken from type-material. New host-plant associations and distribution data to Chinavia species in Brazil are presented.
\end{abstract}

KEYWORDS. Acrosternum; Nezara; Nezarini; stink bugs; phytophagy.

RESUMO. O gênero Chinavia Orian (Hemiptera, Pentatomidae, Pentatominae) no Brasil, com chave pictórica para os adultos. Chinavia Orian é um dos gêneros mais diversos da subfamília Pentatominae, distribuído nas regiões Afrotropical, Neártica e Neotropical. Para o Brasil, são conhecidas 32 espécies, dentre as quais 18 são endêmicas. Do total de espécies com registro para o Brasil, 18 têm algum tipo de registro com plantas-hospedeiras, a maioria delas cultivadas; apenas seis espécies têm os imaturos conhecidos ou algum aspecto de sua biologia estudado. Neste trabalho, é fornecida uma chave pictórica para os adultos das espécies registradas no Brasil, acompanhada da diagnose comparada de cada uma delas, além das informações disponíveis na literatura sobre imaturos e biologia das espécies. Duas novas sinonímias são propostas: Acrosternum (Chinavia) bellum Rolston, 1983 é sinônimo júnior de Chinavia nigrodorsata (Breddin, 1903) e Acrosternum (Chinavia) panizzii Frey-da-Silva \& Grazia, 2001 é sinônimo júnior de Chinavia obstinata (Stål, 1860). Chinavia nigritarsis (Stål, 1872), anteriormente considerada sinônimo júnior de Chinavia gravis (Walker, 1867), é revalidada. Fotografias coloridas do aspecto dorsal de todas as espécies são fornecidas, a maioria delas confeccionadas a partir do material-tipo estudado. Novos registros de distribuição geográfica e de associação com plantas-hospedeiras no Brasil são apresentados.

PALAVRAS-CHAVE. Acrosternum; Nezara; Nezarini; percevejos-do-mato; fitofagia.

O gênero Chinavia Orian, até pouco tempo tratado como subgênero de Acrosternum Fieber (Schwertner \& Grazia 2006a), reúne espécies de percevejos-do-mato bastante comuns, de tamanho médio (9-19 mm) e coloração geral verde, com distribuição nas regiões Afrotropical, Neártica e Neotropical (Schwertner \& Grazia 2006a; b). Exclusivamente fitófagas, várias espécies são registradas sobre plantas cultivadas, algumas delas consideradas pragas (Panizzi et al. 2000; Schwertner \& Grazia 2002). Na região Neotropical, além do trabalho de revisão de Rolston (1983) e de espécies descritas recentemente (Eger 1988; Frey-da-Silva \& Grazia 2001; Schwertner \& Grazia 2006b; Grazia et al. 2006), são conhecidas as formas imaturas e aspectos biológicos de algumas espécies (Matesco et al. 2007). No entanto, a maior parte das espécies do gênero permanece conhecida com base somente na descrição dos adultos. A grande diversidade deste táxon no continente americano (cerca de 70 espécies conhecidas), a semelhança da morfologia geral entre suas espécies e com o percevejo-verde-da-soja [Nezara viridula (Linnaeus)] e a falta de uma revisão taxonômica recente, torna a identificação das espécies de Chinavia difícil, restringindo possíveis registros, o acesso às informações sobre elas e, consequientemente, um maior número de estudos nesse grupo.

Este trabalho apresenta uma síntese sobre o conhecimento do gênero Chinavia no Brasil, incluindo uma chave pictórica para identificação dos adultos de todas as espécies registradas para o país. São fornecidas ainda a diagnose comparada para cada uma delas e discutidas as informações sobre imaturos e biologia disponíveis na literatura. A partir do estudo de materialtipo, novos arranjos taxonômicos são propostos.

\section{MATERIALE MÉTODOS}

Foram incluídas na chave, além de todas as espécies com 
registro no Brasil, algumas com registro apenas nos países próximos (p.ex. Argentina, Paraguai e Uruguai), mas que poderão ser eventualmente encontradas dentro dos limites do país. Para algumas espécies [p.ex. Chinavia abnormis (Berg)], o material analisado não confirmou a distribuição para o Brasil citada na literatura. Essas e outras situações são discutidas individualmente ao longo do texto. Comentários sobre a distribuição de cada espécie foram feitos apenas para aquelas que apresentam boa representatividade nas coleções estudadas.

Holótipos ou lectótipos de quase todas as espécies foram estudados; apenas $C$. longicorialis e C. rogenhoferi, espécies de fácil reconhecimento, foram identificadas a partir do trabalho de Rolston (1983), que descreveu e ilustrou essas espécies com base nos respectivos espécimes-tipo. Além do estudo do material-tipo, a caracterização das espécies foi baseada em material conservado à seco em coleções do Brasil e do exterior. Exemplares de todas as espécies foram examinados, e pertencem às seguintes coleções (acrônimos e curadores das coleções entre parênteses): American Museum of Natural History, Nova York, EUA (AMNH, R. T. Schuh); Centro Nacional de Pesquisas da Soja, EMBRAPA, Londrina, Paraná, Brasil (CNPS, A. R. Panizzi); Coleção Entomológica, Universidade de Brasília, Brasília, Brasil (UNB, C.E.G. Pinheiro); Coleção Entomológica, Universidade Federal de Viçosa, Viçosa, Brasil (UFV, P. S. Fiuza-Ferreira); Coleção particular de D. A. Rider, Department of Entomology, North Dakota State University, Fargo, EUA (DAR, D. A. Rider); Coleção de Entomologia Pe. J. S. Moure, Departamento de Zoologia, Universidade Federal do Paraná, Curitiba, Paraná, Brasil (UFPR, L. Marinoni); Departamento de Zoologia, Universidade Federal do Rio Grande do Sul, Porto Alegre, Brasil (DZRS, J. Grazia); Deutsche Entomologische Institut, Eberswald, Alemanha (DEI, E. K. Groll); Embrapa Cerrado, Planaltina, Brasil (CPAC); Facultad de Ciencias Naturales y Museo, Universidad Nacional de La Plata, La Plata, Argentina (MLP, M. C. Coscarón); Coleção Zoológica Prof. Paulo Burnheim, Universidade Federal do Amazonas, Manaus, Amazonas, Brasil (CZPB, N. O. Aguiar); Instituto Alexander von Humboldt, Santa Fé de Bogotá, Colômbia (IAVH, J. E. Castillo); Instituto Miguel Lillo, Universidade Nacional de Tucuman, Argentina (IML, M. V. A. de Toledo); Instituto Nacional de Pesquisas da Amazônia, Manaus, Amazonas, Brasil (INPA, J. A. Rafael); Instituto Oswaldo Cruz, Rio de Janeiro, Brasil (FIOC, $†$ S. Oliveira); Museo Argentino de Ciencias Naturales Bernardino Rivadavia, Buenos Aires, Argentina (MACN, A. Bachmann); Museo del Instituto de Zoologia Agrícola, Maracay, Venezuela (MIZA, E. Osuna); Museo Javeriano de Historia Natural, Pontificia Universidad Javeriana, Bogotá, Colômbia (MUJ); Museo Regionale di Scienze Naturali di Torino, Torino, Itália (MRSN, P. L. Scaramozzino); Museu Anchieta, Colégio Anchieta, Porto Alegre, Rio Grande do Sul, Brasil (MGAP, F. Becker); Museu de Ciências Naturais, Fundação Zoobotânica do RS, Porto Alegre, Rio Grande do Sul, Brasil (MCNZ, A. Barcellos); Museu de História Natural, Universidade Estadual de Campinas, Campinas, Brasil (ZUEC, K. Brown); Museu de Zoologia da Universidade de São Paulo, São Paulo, Brasil (MZSP, C. Costa); Museu Nacional, Universidade Federal do Rio de Janeiro, Rio de Janeiro, Brasil (MNRJ, L. Costa); Museum National d'Histoire Naturelle, Paris, França (MNHN, D. Plüot-Sigwald); Museum Paraense Emílio Goeldi, Belém, Brasil (MPEG, A. Harada); National Museum of Natural History, Washington D. C., EUA (NMNH, T. Henry); Naturhistoriska Riksmuseet, Estocolmo, Suécia (NRM, B. Viklund); The Natural History Museum, Londres, Inglaterra (BMNH, M. Web).

O levantamento das características utilizadas na chave foi realizado com base na análise da morfologia geral externa dos espécimes estudados. Estas características, conservativas para a maioria das espécies, possibilitam seu fácil reconhecimento; espécies que eventualmente apresentaram polimorfismo para alguma das características foram incluídas em mais de um passo da chave. Características de genitália, por serem de difícil visualização, foram evitadas neste trabalho, apesar de sua importância para estudos taxonômicos e filogenéticos dentro da família Pentatomidae. Os desenhos utilizados na chave foram confeccionados para representar especificamente as estruturas descritas em cada passo, não devem ser utilizados para identificar outras características na respectiva espécie que está sendo identificada. As estruturas utilizadas e a terminologia das mesmas estão detalhadas nas Figs. 1 e 2.

Para a maioria dos registros das plantas, não foi possível estabelecer o tipo de associação dessas com a espécie de Chinavia relacionada (por ex. sítio de alimentação das ninfas/ adultos ou sítio de acasalamento). Esses registros devem ser considerados como informação primária de uma possível associação com essas plantas. A classificação para as famílias de plantas seguiu Souza \& Lorenzi (2005).

Ilustrações foram confeccionadas com auxílio de câmaraclara acoplada a estereomicroscópio ou máquina fotográfica digital. Sempre que possível, o material-tipo estudado foi utilizado para confecção das fotografias (indicação nas legendas das figuras). Na seção de distribuição das espécies, os estados brasileiros são citados utilizando-se as siglas oficiais.

\section{RESULTADOS EDISCUSSÃO}

Arranjos taxonômicos.

O exame dos holótipos das espécies de Chinavia com registro para o Brasil, principalmente com base no estudo comparado da genitália, permitiu estabelecer duas novas sinonímias e revalidar o status de uma espécie com registro para o Brasil. Desta forma, Acrosternum (Chinavia) bellum Rolston, 1983 é considerada sinônimo júnior de Chinavia nigrodorsata (Breddin, 1901) e Acrosternum (Chinavia) panizzii Frey-da-Silva \& Grazia, 2001 é considerada sinônimo júnior de Chinavia obstinata (Stål, 1860); Chinavia nigritarsis (Stål, 1872) é retirada da sinonímia de Chinavia gravis (Walker, 1867), sendo considerada espécie válida. 
Tabela I. Lista das espécies incluídas no gênero Chinavia Orian com registro para o Brasil.

\section{Espécie}

Chinavia abnormis (Berg, 1892)*

Chinavia armigera (Stål, 1859)

Chinavia aseada (Rolston, 1983)

Chinavia bipunctula (Stål, 1872)

Chinavia brasicola (Rolston, 1983)

Chinavia cearensis Schwertner \& Grazia, 2006

Chinavia dallasi (Distant, 1900)*

Chinavia difficilis (Stål, 1860)

Chinavia erythrocnemis (Berg, 1878)

Chinavia esmeralda (Rolston, 1983)

Chinavia fuscopunctata (Breddin, 1901)

Chinavia geniculata (Dallas, 1851)

Chinavia gravis (Walker, 1867)

Chinavia herbida (Stål, 1859)*

Chinavia hilaris (Say, 1831)*

Chinavia immaculata (Frey-da-Silva \& Grazia, 2001)

Chinavia impicticornis (Stål, 1872)

Chinavia longicorialis (Breddin, 1901)

Chinavia marginata (Palisot de Beuvois, 1805)*

Chinavia musiva (Berg, 1978)

Chinavia napaea (Stål, 1972)

Chinavia nigritarsis (Stål, 1972) reval.

Chinavia nigrodorsata (Breddin, 1901)

Chinavia nigropicta (Breddin, 1906)

Chinavia obstinata (Stål, 1860)

Chinavia pengue (Rolston, 1983)

Chinavia plaumanni (Rolston, 1983)

Chinavia pontagrossensis (Frey-da-Silva \& Grazia, 2001)

Chinavia rideri (Frey-da-Silva \& Grazia, 2001)

Chinavia rogenhoferi (Stål, 1872)

Chinavia rufitibia Schwertner \& Grazia, 2006

Chinavia runaspis (Dallas, 1851)

Chinavia schuhi Schwertner \& Grazia, 2006

Chinavia sebastiaoi Schwertner \& Grazia, 2006

Chinavia simplicis (Rolston, 1983)

Chinavia tuiucauna Schwertner \& Grazia, 2006

Chinavia ubica (Rolston, 1983)

Chinavia vanduzeei Schwertner \& Grazia, 2006

* registro não confirmado para o Brasil neste trabalho.

\section{Espécies de Chinavia no Brasil.}

$\mathrm{Na}$ literatura é encontrado registro de 37 espécies de Chinavia para o Brasil (Tabela I), já incluindo os novos arranjos taxonômicos propostos neste trabalho. O material examinado não confirmou o registro de cinco delas. As espécies $C$. abnormis, $C$. dallasi e $C$. herbida ocorrem em regiões de países vizinhos próximas ao Brasil, foram incluídas na chave pictórica e são discutidas junto com as demais espécies. As espécies $C$. hilaris e $C$. marginata não têm distribuição em localidades próximas ao Brasil, não foram incluídas na chave pictórica e na seção de diagnose e discussão das espécies.

A espécie neártica $C$. hilaris é citada na literatura associada à soja no Brasil (Zucchi et al. 1993; Magrini et al. 1996; Gallo et al. 2002), mas até o momento não foram encontradas em coleções espécimes que comprovem esse registro (Schwertner \& Grazia 2002). A ilustração dos imaturos e do adulto de $C$. hilaris (citada como Acrosternum hilare) em Gallo et al. (2002) trata-se efetivamente de $C$. impicticornis.

A espécie C. marginata é ilustrada por Costa Lima (1940, p. 58) e associada a leguminosas e solanáceas nos estados de MG, RJ e RS por Bertels (1962) e Silva et al. (1968) (como Nezara marginata). Grazia (1977) não teve acesso ao material estudado por aqueles autores para confirmar a identificação da espécie, cuja distribuição conhecida inclui desde o sul dos Estados Unidos até as regiões do norte da Colômbia e Venezuela (Rolston 1983; Schwertner dados não publicados). Nenhuma das coleções examinadas nesse trabalho corroborou o registro dessa espécie para o Brasil; a ilustração de Costa Lima (1940), cuja legenda indica C. marginata (citada como Nezara marginata), aparentemente trata-se de C. ubica.

Desse modo, 32 espécies do gênero Chinavia com registro para o Brasil são confirmadas no presente trabalho, 18 delas com distribuição restrita aos limites políticos do país. Apenas as espécies $C$. impicticornis, $C$. runaspis e $C$. ubica possuem ampla distribuição em todo Brasil, sendo bastante comuns em coleções; as demais apresentam distribuição restrita a certas regiões do país ou da América do Sul, algumas pouco representadas em coleções.

Quanto à morfologia dos imaturos, é possível reconhecer o gênero já nos estágios de ovo e ninfa (Schwertner et al. 2002; Matesco et al. 2007). Os resultados encontrados na literatura indicam, ainda, que as espécies podem ser identificadas a partir do estágio ninfal, mais facilmente a partir do segundo instar, com base principalmente no padrão de coloração (Matesco et al. 2007). Estágios imaturos de seis das espécies de Chinavia com registro no Brasil são conhecidos (ver discussão para cada espécie).

Em relação à associação com plantas, 18 espécies de
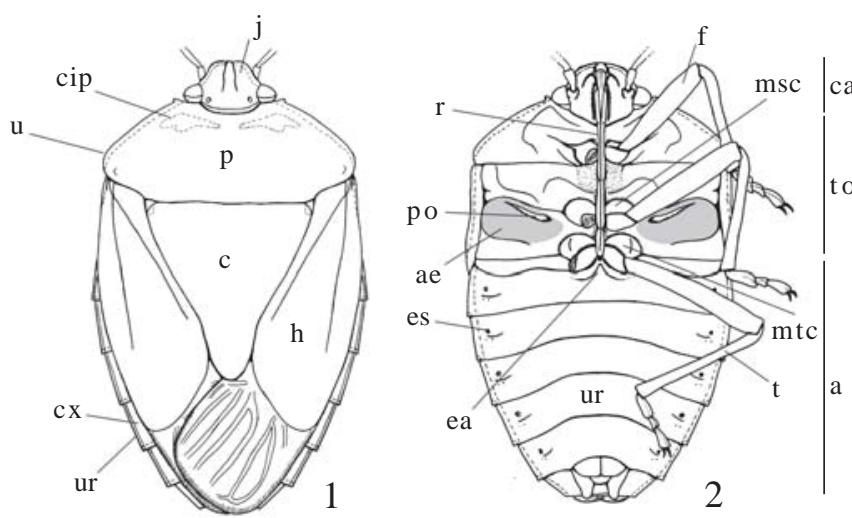

Figs. 1-2. Chinavia sp., aspecto geral. 1, vista dorsal; 2, vista ventral (a, abdome; ae, área evaporatória; ca, cabeça; cip, cicatrizes do pronoto; cpo, comprimento do peritrema ostiolar; cx, conexivo; e, escutelo; ea, espinho abdominal; es, espiráculo; f, fêmur; h, hemiélitro; j, jugas; msc, mesocoxa; mtc, metacoxa; p, pronoto; po, peritrema ostiolar; r, rostro; t, tíbia; to, tórax; u, ângulo umeral do pronoto; ur, urosternito). 
Tabela II. Lista de plantas registradas como possíveis hospedeiras para as espécies de Chinavia listadas na chave pictórica.

\begin{tabular}{|c|c|c|c|}
\hline Espécie & Família & Planta & Referência* \\
\hline C. abnormis & Solanaceae & Solanum sp. & 19 \\
\hline \multirow[t]{5}{*}{ C. armigera } & Aquifoliacea & Ilex paraguariensis A. St. Hil. (erva-mate) & 21 \\
\hline & Chenopodiacea & Beta vulgaris L. (beterraba) & 20 \\
\hline & Fabaceae & Glycine max (L.) Merril (soja) & 1 \\
\hline & Malvaceae & Gossypium hirsutum L. (algodão) & 20 \\
\hline & Poacea & Oryza sativa L. (arroz) & 20 \\
\hline \multirow[t]{9}{*}{ C. aseada } & Asteraceae & Helianthus annuus L. (girassol) & 10 \\
\hline & Cruciferae & Brassica napus L. (colza) & 10 \\
\hline & Fabaceae & Aeschynomene rudis Benth. (angiquinho) & 10 \\
\hline & & Pisum sativum L. (ervilha) & 10 \\
\hline & & Phaseolus vulgaris L. (feijão) & 10 \\
\hline & & Lupinus angustifolius L. (tremoço azul) & 10 \\
\hline & & Glycine $\max ($ L.) Merrill (soja) & 3 \\
\hline & Linaceae & Linum usitatissimum L. (linho) & 10 \\
\hline & Rutaceae & Citrus sp. (laranja) & 1 \\
\hline C. brasicola & Dennstaedtiaceae & Dennstaedtia globulifera (Poir.) Hieron & 1 \\
\hline \multirow[t]{7}{*}{ C. erythrocnemis } & Aquifoliacea & Ilex paraguariensis A. St. Hil. (erva-mate) & 4 \\
\hline & Asteraceae & Senecio brasiliensis Less. & 21 \\
\hline & Fabaceae & Glycine $\max (\mathrm{L}$.$) Merrill (soja)$ & 2 \\
\hline & Malvaceae & Hibiscus sp. & 1 \\
\hline & & Brachychiton populneus (Schott \& Endl.) R. Br. & 1 \\
\hline & Passifloraceae & Passiflora sp. & 1 \\
\hline & Scrophulariaceae & Paulownia tomentosa (Thunb.) Sieb. \& Zucc. ex Steud. & 21 \\
\hline \multirow[t]{4}{*}{ C. herbida } & Aquifoliaceae & Ilex paraguariensis A. St. Hil. (erva-mate) & 21 \\
\hline & Asteraceae & Helianthus annuus L. (girassol) & 21 \\
\hline & Cucurbitaceae & Cucumis melo L. (melão) & 21 \\
\hline & Fabaceae & Glycine $\max (\mathrm{L}$.$) Merrill (soja)$ & 21 \\
\hline \multirow[t]{15}{*}{ C. impicticornis } & Aquifoliaceae & Ilex paraguariensis A. St. Hil. (erva-mate) & 1 \\
\hline & Asteraceae & Emilia sonchifolia (L.) DC. (serralha) & 9 \\
\hline & Fabaceae & Crotalaria incana $\mathrm{L}$. & 24 \\
\hline & & Crotalaria pallida Aiton & 24 \\
\hline & & Phaseolus vulgaris L. (feijão) & 1 \\
\hline & & Glycine $\max (\mathrm{L}$.$) Merrill (soja)$ & $9,10,16,26$ \\
\hline & & Psophocarpus tetragonolobus (L.) DC. & 1 \\
\hline & & Vigna unguiculata (L.) Walp. (caupi) & 23 \\
\hline & Malvaceae & Gossypium hirsutum L. (algodão) & 26 \\
\hline & & Theobroma cacao (cacau) & 8 \\
\hline & Myrtaceae & Psidium guajava L. (goiaba) & 1 \\
\hline & Oleaceae & Ligustrum lucidum (Ait.) (ligustro). & 17 \\
\hline & Passifloraceae & Passiflora sp. (maracujá) & 1 \\
\hline & Poaceae & Oryza sativa L. (arroz) & 26 \\
\hline & Proteaceae & Macadamia sp & 1 \\
\hline \multirow[t]{3}{*}{ C. longicorialis } & Rhamnaceae & Scutia buxifolia & 1 \\
\hline & Rosaceae & Prunus sp. (pêssego) & 1 \\
\hline & Smilacaceae & Smilax sp. & 1 \\
\hline \multirow[t]{4}{*}{ C. musiva } & Anacardiaceae & Schinus sp. & 1 \\
\hline & Fabaceae & Mimosa bimucronata Burkart & 1 \\
\hline & & Prosopis caldenia (DC) Kuntze & 1 \\
\hline & Rutacea & Citrus sp. & 1 \\
\hline \multirow[t]{10}{*}{ C. nigrodorsata } & Aizoaceae & Tetragonia tetragonioides & 10 \\
\hline & Compositae & Cynara scolymus L. (alcachofra) & 13 \\
\hline & & Helianthus annuus L. (girassol) & 10 \\
\hline & Cruciferae & Brassica napus L. (colza) & 10 \\
\hline & & Brassica oleraceae L. (couve) & 10,13 \\
\hline & Fabaceae & Aeschynomene rudis Benth. (angiquinho) & 6,10 \\
\hline & & Glycine $\max$ (L.) Merrill (soja) & $5,10,12,13,18$ \\
\hline & & Lens esculenta Noench (lentilha) & 11 \\
\hline & & Lupinus albus L. (tremoço branco) & 10 \\
\hline & & Phaseolus vulgaris L. (feijão) & 10 \\
\hline
\end{tabular}


Tabela II. Continuação.

\begin{tabular}{|c|c|c|c|}
\hline Espécie & Família & Planta & Referência* \\
\hline & Fabaceae & Mimosa invisa Mart. & 1 \\
\hline & Linaceae & Linum usitatissimum L. (linho) & 6 \\
\hline & Poaceae & Oryza sativa L. (arroz) & 10,13 \\
\hline & & Triticum aestivum L. (trigo) & 10 \\
\hline & Malvaceae & Abelmoschus esculentus (L.) (quiabo) & 10,13 \\
\hline & Solanaceae & Nicotiana tabacum L. (fumo) & 10 \\
\hline & & Solanum sisymbriifolium Lam. (joá) & 6,13 \\
\hline & Umbelliferae & Foeniculum vulgare Mill. (funcho) & 13 \\
\hline \multirow[t]{2}{*}{ C. obstinata } & Fabaceae & Glycine $\max (\mathrm{L}$.$) Merrill (soja)$ & 1 \\
\hline & Passifloraceae & Passiflora edulis Sims (maracujá-amarelo) & 14 \\
\hline \multirow[t]{7}{*}{ C. pengue } & Aquifoliaceae & Ilex paraguariensis A. St. Hil. (erva-mate) & $4 * *$ \\
\hline & Cruciferae & Brassica napus L. (colza) & 10 \\
\hline & Fabaceae & Glycine max (L.) Merrill (soja) & 10 \\
\hline & & Lupinus albus L. (tremoço branco) & 10 \\
\hline & & Crotalaria pallida Aiton*** & 15 \\
\hline & Malvaceae & Gossypium hirsutum L. (algodão) & 15 \\
\hline & Solanaceae & Solanum sp. & 15 \\
\hline C. pontagrossensis & Fabaceae & Glycine $\max (\mathrm{L}$.$) Merrill (soja)$ & 7 \\
\hline \multirow[t]{2}{*}{ C. rideri } & Fabaceae & Bauhinia sp. (pata-de-vaca) & 7 \\
\hline & & Glycine $\max (\mathrm{L}$.$) Merrill (soja)$ & 7 \\
\hline C. rufitibia & Fabaceae & Glycine $\max (\mathrm{L}$.$) Merrill (soja)$ & 25 \\
\hline \multirow[t]{2}{*}{ C. runaspis } & Palmaceae & Elaeis sp. (dendê) & 1 \\
\hline & Oleaceae & Ligustrum lucidum (Ait.) (ligustro) & 17 \\
\hline C. tuiucauna & Malvaceae & Theobroma cacao (cacau) & 25 \\
\hline \multirow[t]{9}{*}{ C. ubica } & Fabaceae & Canavalia rosea (Sw.) DC. & 24 \\
\hline & & Crotalaria incana $\mathrm{L}$. & 24 \\
\hline & & Crotalaria pallida Aiton & 24 \\
\hline & & Glycine $\max (\mathrm{L}$.$) Merrill (soja)$ & 16,22 \\
\hline & & Vigna unguiculata (L.) Walp. (caupi) & 24 \\
\hline & & Cajanus cajan (L.) Millsp. (guandú) & 24 \\
\hline & & Phaseolus vulgaris L. (feijão) & 24 \\
\hline & Malvaceae & Gossypium hirsutum L. (algodão) & 1 \\
\hline & Solanaceae & Lycopersicon esculentum Mill. (tomate) & 1 \\
\hline
\end{tabular}

*1. este trabalho (registro novo); 2. Bertels \& Ferreira 1973; 3. Carvalho et al. 1995; 4. Coll \& Saini 1992; 5. Costa \& Link 1974; 6. Vecchio et al 1988; 7. Frey-da-Silva \& Grazia 2001; 8. Grazia 1979; 9. Grazia et al. 1982; 10. Link \& Grazia 1987; 11. Link 1979; 12. Link et al. $1973 ; 13$. Lopes et al. 1974; 14. Matesco et al. 2003; 15. Matesco et al. no prelo; 16. Panizzi 2002; 17. Panizzi \& Grazia 2001; 18. Panizzi \& Smith 1976; 19. Pennington 1919; 20. Quintanilla et al. 1976; 21. Quintanilla et al. 1981; 22. Rolston 1983; 23. Santos \& Quinderé 1988; 24. Schwertner et al. 2002; 25. Schwertner \& Grazia 2006b; 26. Silva et al. 1968.

** Coll \& Saini (1992) citam erva-mate como planta hospedeira de C. impicticornis, no entanto as ilustrações permitem confirmar que a espécie citada é $C$. pengue.

*** citada como Crotalaria mucronata Desv.

Chinavia possuem algum tipo de registro, a maioria delas associadas à plantas cultivadas (Tabela II). A partir de dados provenientes da literatura e dos novos registros incluídos neste trabalho, um total de 55 espécies de plantas em 24 famílias foram registradas. A família mais freqüente é Fabaceae, com 13 espécies de Chinavia associadas a essas leguminosas; soja foi a espécie de planta na qual se encontrou maior número de espécies de percevejos associados (Tabela II). Mais da metade das famílias de plantas teve apenas uma espécie de percevejoverde registrada: Aizoaceae, Aquifoliaceae, Chenopodiaceae, Cucurbitaceae, Dennstaedtiaceae, Myrtaceae, Palmaceae, Proteaceae, Rhamnaceae, Rosaceae, Scrophulariaceae,
Smilacaceae e Umbelliferae. Um grande número de espécies de Chinavia no Brasil é registrado em apenas uma família de planta (Tabela II), provavelmente pela ausência deste tipo de dado na maior parte do material depositado em coleções. A associação de $C$. aseada, C. armigera, $C$. erythrocnemis, $C$. impicticornis, $C$. nigrodorsata e $C$. pengue com cinco ou mais famílias de plantas, adicionada aos dados de literatura de outras espécies de Chinavia não registradas para o Brasil (Panizzi 1997; Panizzi et al. 2000), indica que o hábito polífago é a regra entre as espécies desse gênero de percevejos-verdes. Entre as espécies com registro para o Brasil, $C$. nigrodorsata é a espécie com maior número de associações com possíveis 
plantas hospedeiras (17 espécies em nove famílias), seguida de C. impicticornis (14 espécies em oito famílias) (Tabela II).

Outro fator que suportaria a condição polífaga dos percevejos-verdes do gênero Chinavia seriam dados da biologia das ninfas e adultos nessas possíveis plantas hospedeiras. No entanto, poucas espécies de Chinavia têm sua biologia conhecida (Matesco et al. 2007), geralmente em apenas um tipo de alimento. Quando alimentadas com plantas cultivadas de diferentes famílias, $C$. impicticornis e C. ubica sobreviveram e se reproduziram sobre todas as plantas testadas, confirmando seu hábito polífago (Schwertner, dados não publicados). $\mathrm{O}$ mesmo estudo ainda demonstrou que a biologia das espécies varia bastante de acordo com a plantahospedeira utilizada, mesmo em plantas de uma mesma família, fato que parece ser a regra para pentatomídeos (Panizzi et al. 2000) e heterópteros fitófagos em geral (Mitchell 2006).

Das 13 espécies americanas de Chinavia que têm algum aspecto da história de vida conhecido (Matesco et al. 2007), seis são registradas para o Brasil. De acordo com os dados da literatura (Grazia et al. 1982; Vecchio et al. 1988; Avalos \& La Porta 1996; Schwertner et al. 2002; Matesco et al. 2003; 2006; 2007), sob condições controladas de laboratório $\left(24 \pm 1^{\circ} \mathrm{C}, 70\right.$ $\pm 10 \%$ UR, 12-14hL:12-10hE) e utilizando vagens verdes de feijão como alimento padrão, o tempo médio de desenvolvimento do estágio de ovo varia de seis a oito dias e do estágio ninfal de 30 a 45 dias; a mortalidade média durante os estágios imaturos pode variar de 1,6 a 70\%, dependendo da espécie. Em relação aos adultos, a longevidade média pode chegar a mais de 100 dias; fêmeas de diferentes espécies ovipositam em média de 6 a 15 massas de ovos ao longo de sua vida, podendo atingir uma fecundidade média que varia entre as espécies de 80 a 220 ovos. O número de ovos por postura, geralmente em números múltiplos de sete, parece ser fixa na maioria das espécies, com uma moda de 14 ovos por postura (Matesco et al. 2007); C. ubica apresenta o número médio de ovos por postura relacionado ao tipo de alimento utilizado (Schwertner, dados não publicados). Nas diferentes espécies estudadas, a fertilidade média dos ovos pode variar de 70 a 99\%. Para pentatomídeos fitófagos, um determinado alimento pode ser adequado apenas para um dos estágios ou apenas para uma das caracteríticas estudadas (por ex. longevidade do adulto) (Panizzi et al. 2000); evidências mostram que esta seria a regra também entre os percevejosverdes do gênero Chinavia (Schwertner, dados não publicados; Matesco et al. 2003; 2007). O estudo da biologia desses insetos é de extrema importância, uma vez que algumas espécies (por ex. C pengue e C. ubica) podem apresentar rápido desenvolvimento, baixa mortalidade e alto potencial reprodutivo em algumas de suas hospedeiras cultivadas. As características biológicas destas espécies e a relação com os ambientes nos quais são encontradas só poderão ser determinados através de estudos com suas possíveis plantas hospedeiras, sejam elas cultivadas ou selvagens.

Chave pictórica para as espécies de Chinavia Orian com registro para o Brasil.

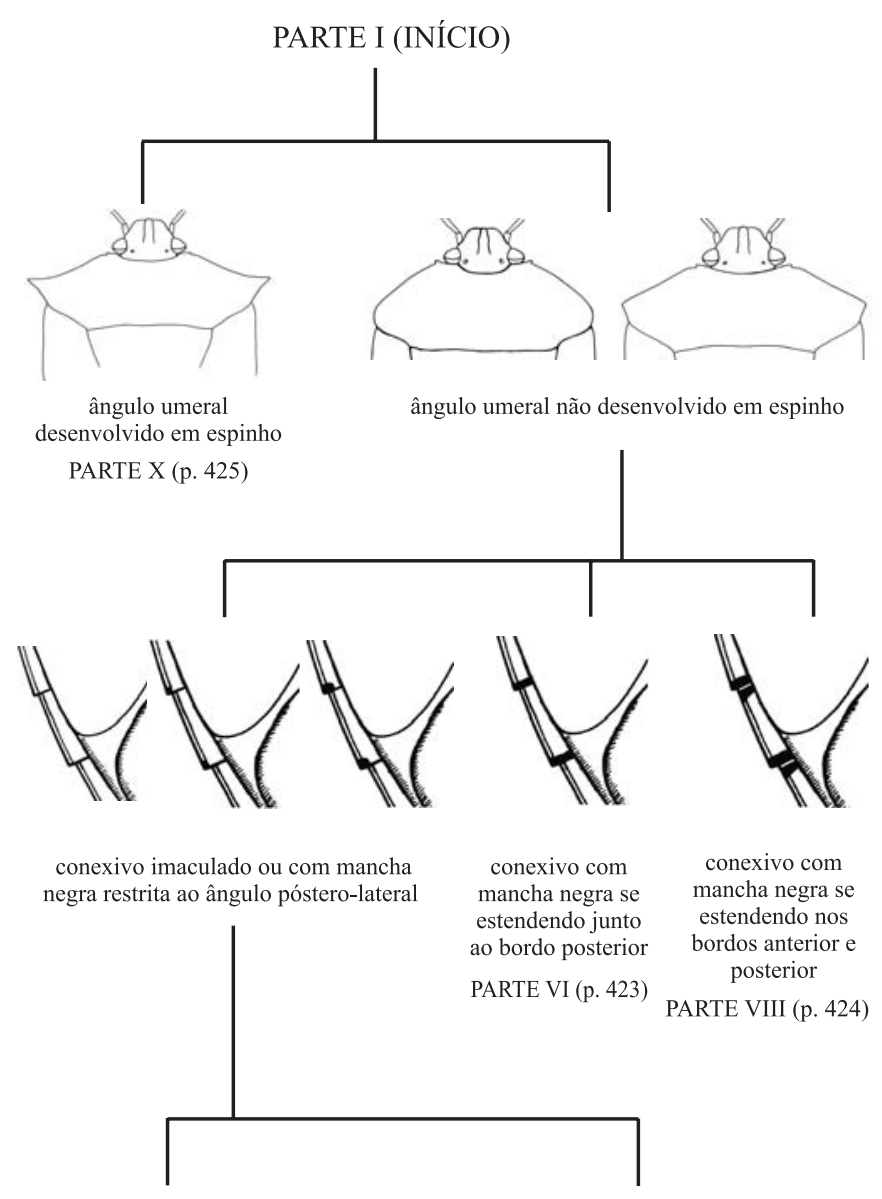

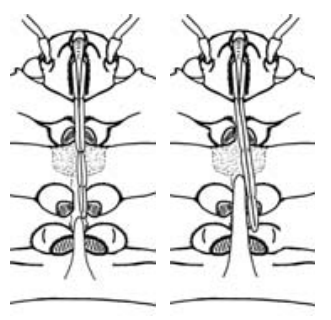

espinho abdominal ultrapassando as metacoxas

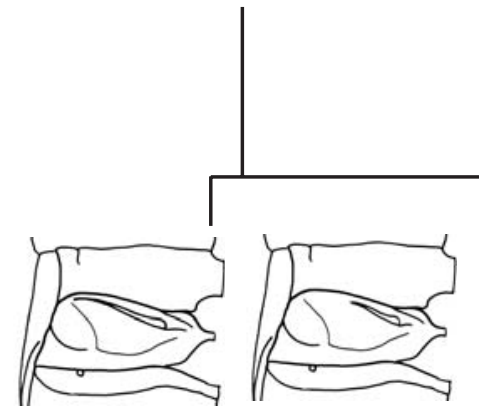

peritrema ostiolar se estendendo além da metade da largura da área evaporatória

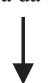

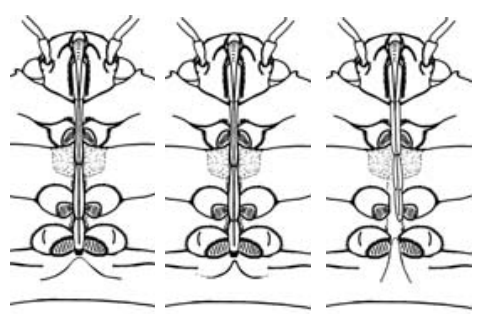

espinho abdominal não atingindo as metacoxas

PARTE II (p. 422)

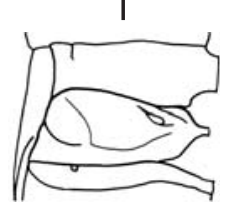

peritrema ostiolar não se estendendo até a metade da largura da área evaporatória C. abnormis 
Cont. PARTE I

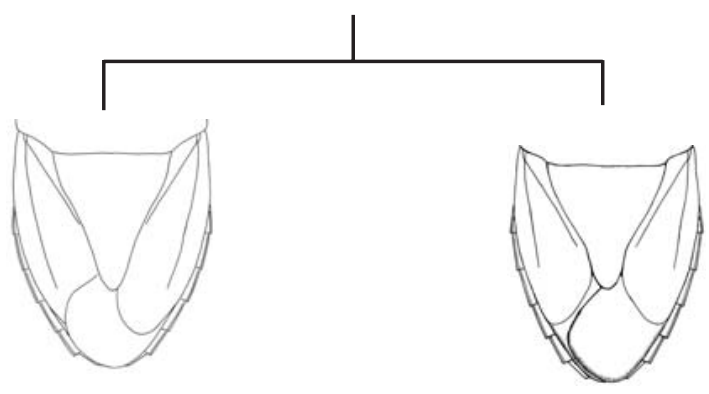

cório longo, atingindo a metade do VII segmento do conexivo

cório não ultrapassando o bordo posterior C. longicorialis

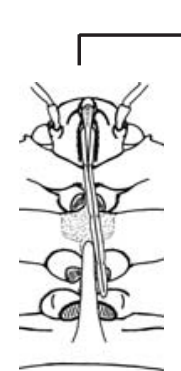

espinho abdominal ultrapassando as mesocoxas C. obstinata

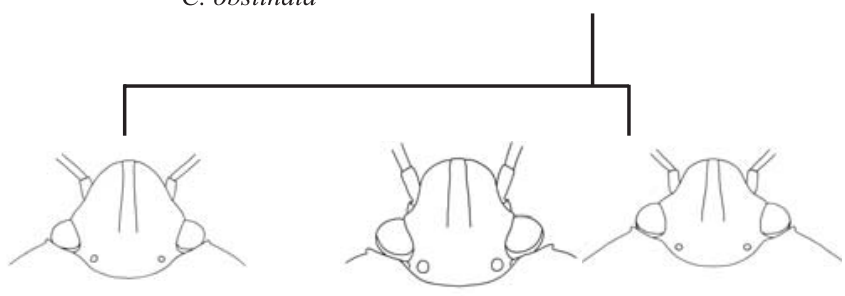

jugas levemente côncavas adiante dos olhos

\section{C. esmeralda}

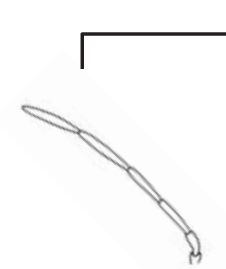

antenas predominantemente verdes, apenas o ápice dos artículos

III, IV e V enegrecidos

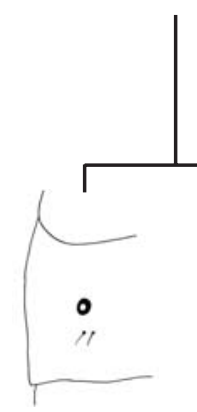

espiráculos escuros

C. difficilis jugas fortemente côncavas adiante dos olhos

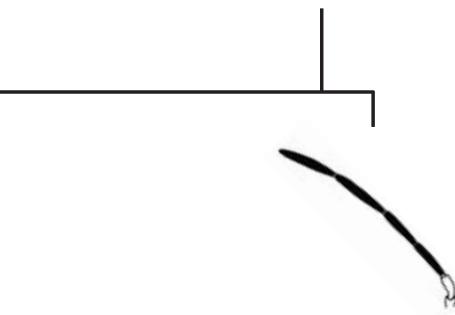

primeiro artículo antenal verde, o restante da antena totalmente enegrecida

C. napaea

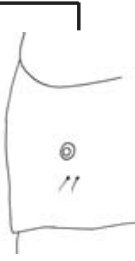

espiráculos verdes ou pálidos C. sebastiaoi

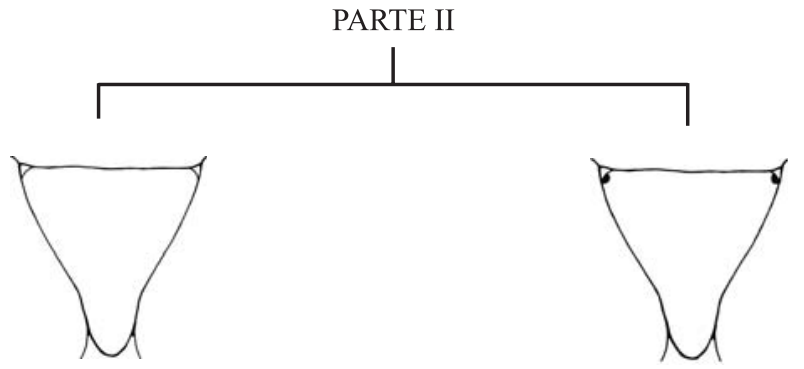

ângulos basais do escutelo imaculados

ângulos basais do escutelo com $1+1$ manchas negras

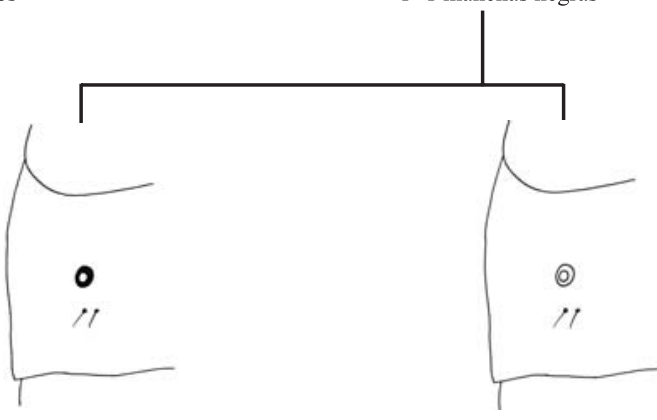

espiráculos negros

C. brasicola

espiráculos verdes ou pálidos

C. impicticornis

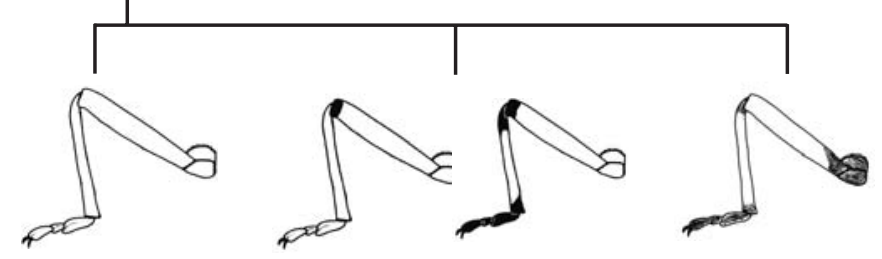

fêmur e tíbia completamente verdes

fêmur com faixa negra apical; tíbia verde, negra ou com a base e o

coxas, base do fêmur, base e ápice da tíbia e tarso, avermelhados

PARTE III (p. 423)

$$
\text { ápice negros }
$$

C. immaculata

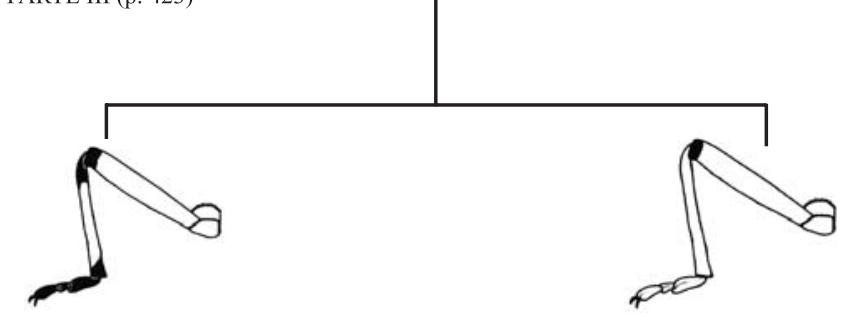

tíbia negra, pelo menos nas regiões basal e apical

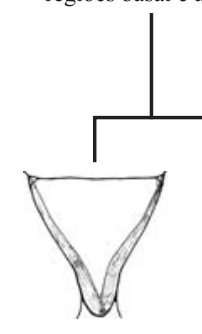

margens laterais do escutelo margeadas de creme

C. nigritarsis

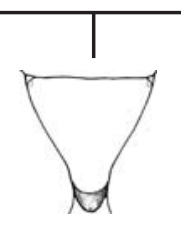

apenas o ápice do escutelo com coloração creme

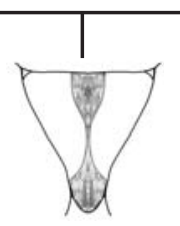

escutelo com uma mancha mediana longitudinal amarelo-creme

C. gravis tíbia completamente verde C. geniculata 


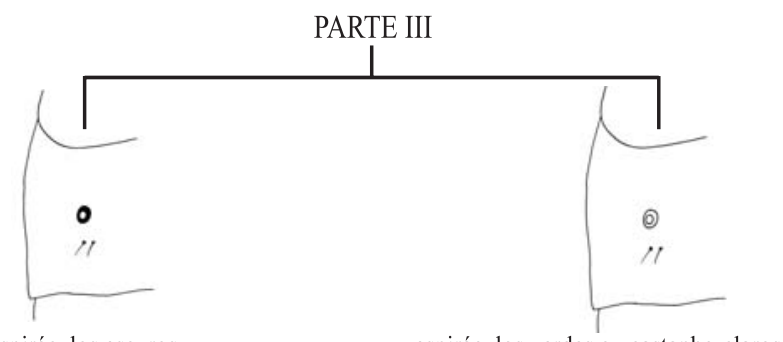

espiráculos escuros espiráculos verdes ou castanho-claros

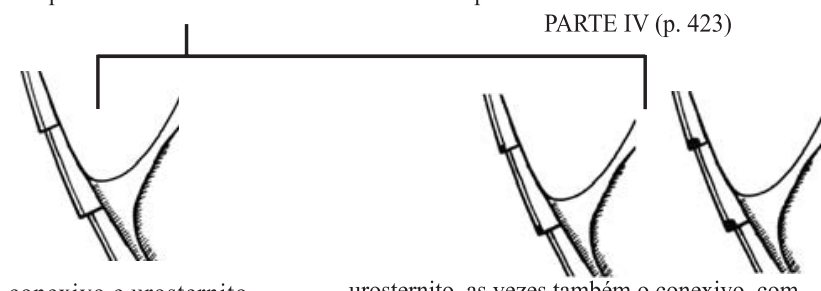

conexivo e urosternito urosternito, as vezes também o conexivo, com

imaculados mancha negra junto ao ângulo póstero-lateral

C. aseada

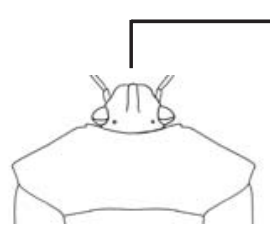

ângulos umerais obtusos C. nigrodorsata
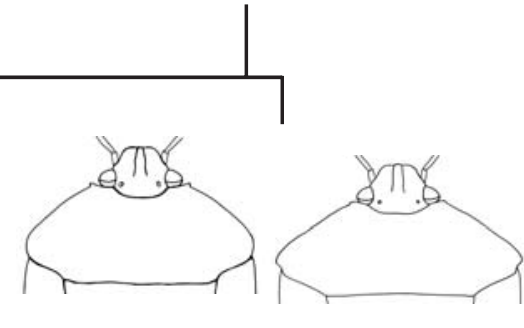

ângulos umerais arredondados

C. ubica

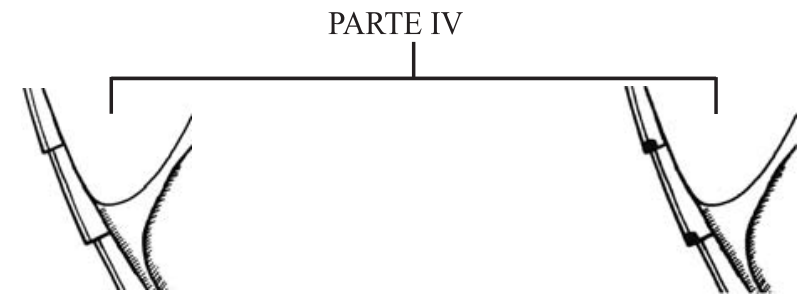

conexivo e urosternito imaculado urosternito e conexivo com mancha negra junto ao ângulo póstero-lateral

C. fuscopunctata

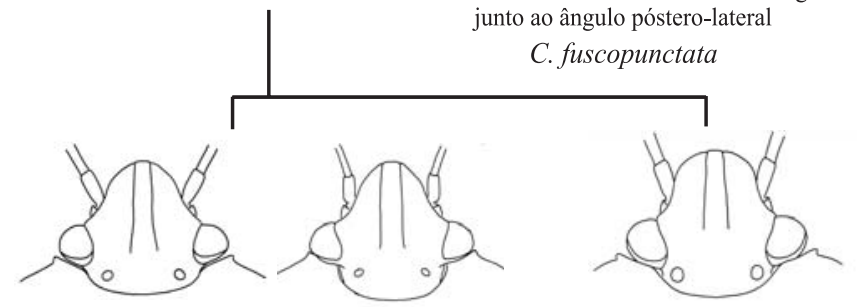

margens das jugas pouco convexas apicalmente; ápice da cabeça subtriangular

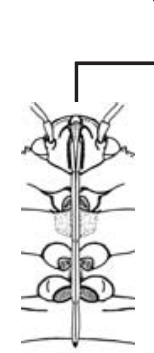

rostro ultrapassando as metacoxas C. schuhi margens das jugas fortemente convexas, apicalmente; ápice da cabeça semicircular PARTE V (p. 423)

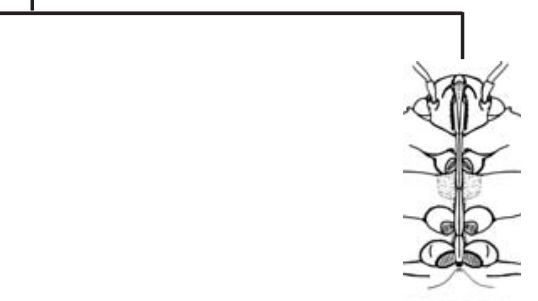

rostro não ultrapassando as metacoxas C. simplicis

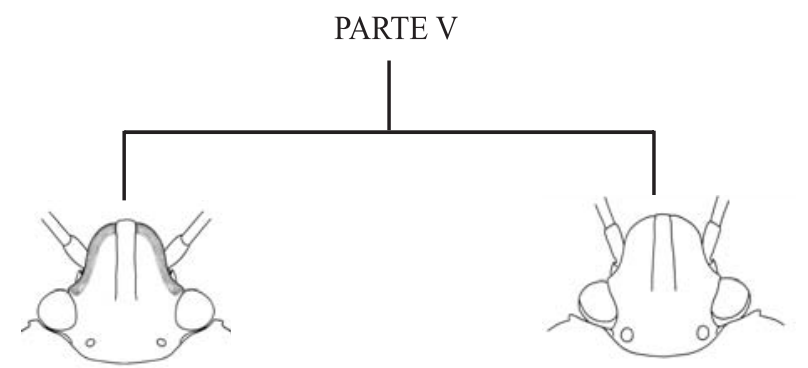

margens laterais das jugas com uma faixa de coloração vermelha

C. cearensis

margens laterais das jugas sem coloração diferenciada

C. sebastiaoi

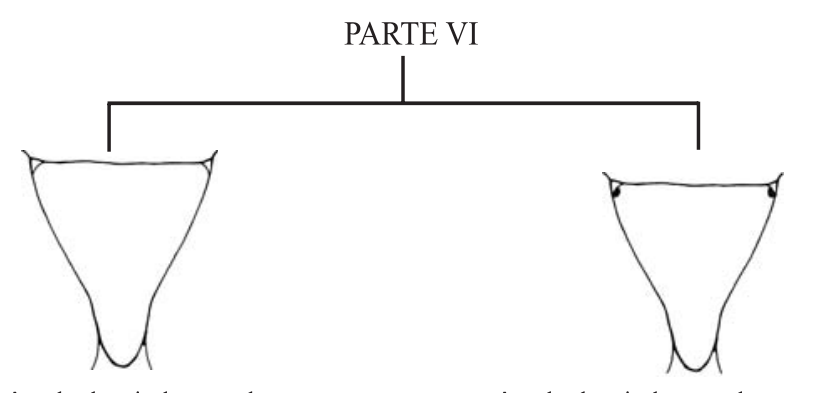

ângulos basais do escutelo imaculados

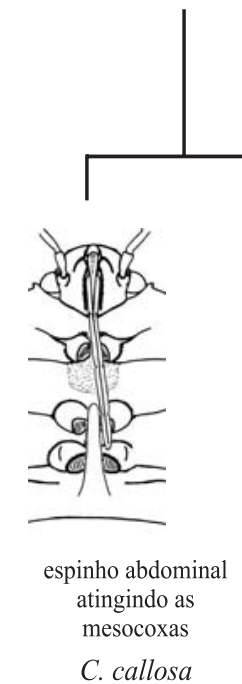

C. callosa

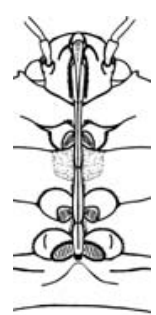

espinho abdomina inconspícuo, formando um tubérculo rombo

C. plaummani ângulos basais do escutelo com 1+1 manchas negras

PARTE VII (p. 424)

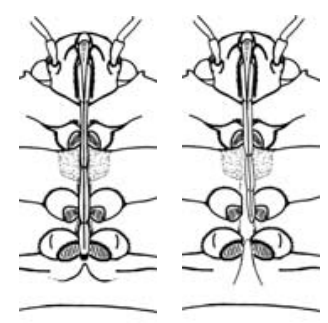

espinho abdominal conspícuo mas nunca ultrapassando as metacoxas

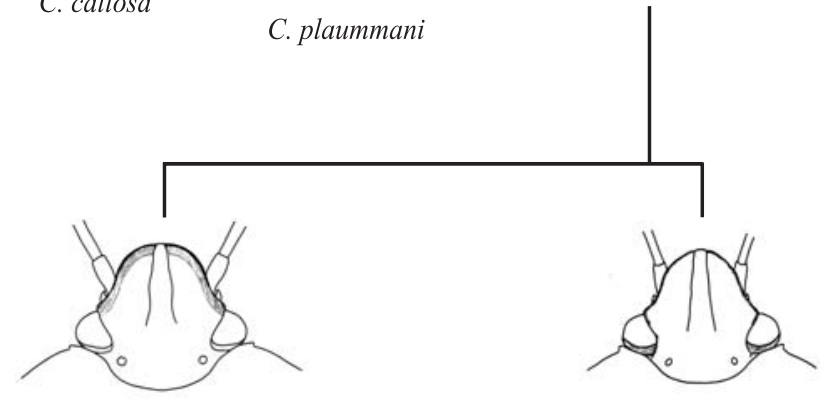

margens das jugas com faixa interna de coloração avermelhada e uma faixa externa, mais estreita, negra

$$
\text { C. pengue }
$$

margens das jugas com uma estreita faixa amarelada junto à borda

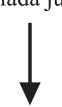




\section{Cont. PARTE VI}

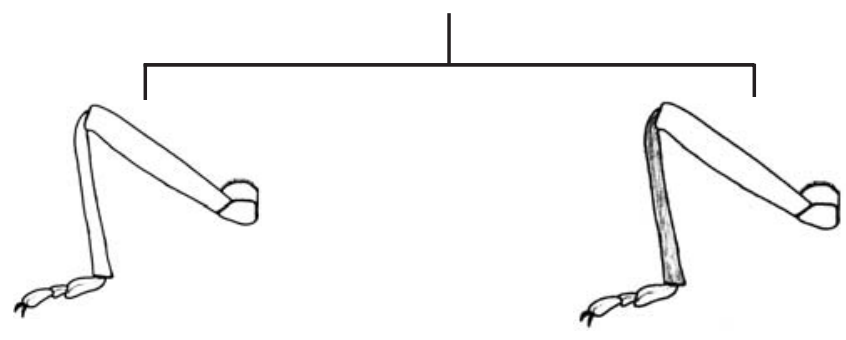

tíbias verdes ou ferrugíneas

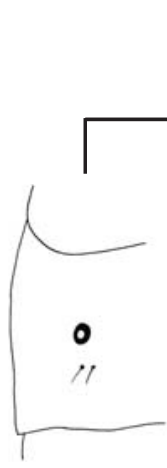

espiráculos negros

C. bipunctula

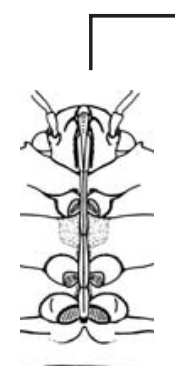

espinho abdominal raramente atingindo as metacoxas

C. impicticornis tíbias avermelhadas

C. rufitibia

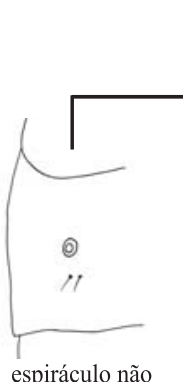

espiráculo não acompanhado por calo

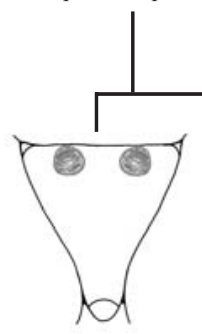

1+1 manchas circulares creme-amareladas junto à base do escutelo

C. rogenhoferi
PARTE VIII 


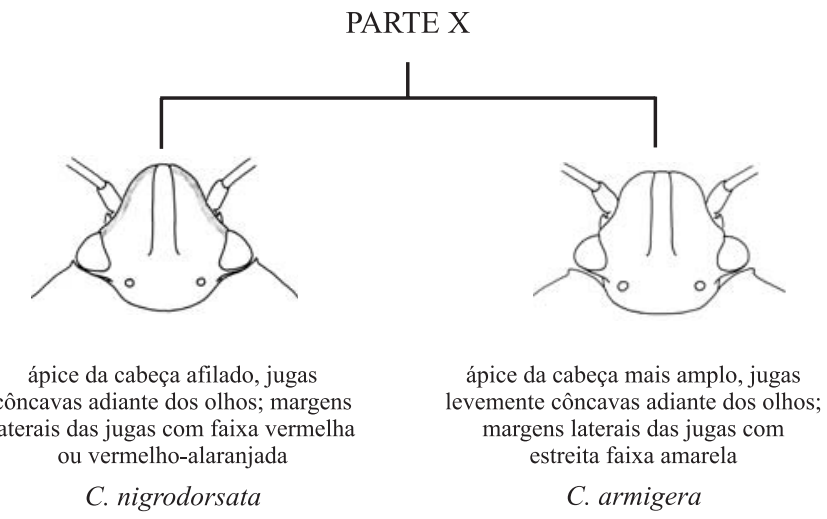

Chinavia abnormis (Berg)

(Fig. 3)

Espécie de coloração predominantemente verde, com uma faixa longitudinal mediana e margens do corpo de coloração amarelada. Pontuação da face dorsal profunda, dando aspecto rugoso ao corpo. Corpo alongado (comprimento maior que 1,5 vezes a largura), peritrema ostiolar não atingindo a metade da largura da área evaporatória, espinho abdominal ultrapassando as metacoxas e espiráculo abdominal circundado por um calo amarelo bem desenvolvido. O percevejo-verde-da-soja [Nezara viridula (Linnaeus, 1758)], espécie reconhecida como invasora na região neotropical, também apresenta peritrema ostiolar curto, mas a pontuação do corpo é mais rasa, o espinho abdominal é curto e inconspícuo, o calo amarelo junto aos espiráculos está ausente. Pirán (1968) e Rolston (1983) registraram C. abnormis (como Acrosternum abnorme) para o sul do Brasil, no entanto o material analisado para este trabalho não confirma essa distribuição. Registrada sobre solanáceas na Argentina (Tabela II). Tamanho dos adultos: 11-13mm.

Distribuição: Uruguai, Argentina.

\section{Chinavia armigera (Stål)} (Fig. 4)

Espécie de coloração geral verde a verde-clara, com uma estreita faixa longitudinal mediana e margens do corpo de coloração amarelada; às vezes, pode estar presente uma estreita faixa de coloração vermelho-clara junto às margens das jugas. Ângulos umerais desenvolvidos em espinho; distingue-se de C. nigrodorsata pelas jugas mais amplas e pelo padrão de coloração da face dorsal. Vários registros dessa espécie para o sul do Brasil (como Acrosternum armigerum), anteriores à revisão de Rolston (1983), tratavam-se efetivamente de $C$. nigrodorsata (Vecchio et al. 1988; ver diagnose para $C$. nigrodorsata). Registros em soja no RS e em plantas de outras cinco famílias (Tabela II) indicam o hábito polífago dessa espécie. Tamanho dos adultos: 10-13mm.

Distribuição: Brasil (RS), Argentina, Uruguai.
Chinavia aseada (Rolston)

(Fig. 5)

Espécie de coloração geral verde, com as margens do corpo, bordos da cabeça, do pronoto, do hemiélitro e do conexivo vermelho a vermelho-claro; cicatrizes do pronoto e ângulos basais do escutelo imaculados. Semelhante a $C$. nigrodorsata, C. simplicis e C. ubica, distinguindo-se destas pelo urosternito e conexivo sem manchas negras, espinho abdominal inconspícuo e pela ausência do calo amarelo junto ao espiráculo. A distribuição na descrição original da espécie incluía apenas o sul do Brasil (RS) e norte da Argentina (Rolston 1983), onde é bastante coletada. Carvalho et al. (1995) ampliaram a distribuição para o DF (como Acrosternum aseadum) o que, incluindo os novos registros deste trabalho (PA, MT e PR), fazem de C. aseada uma das espécies de Chinavia com ampla distribuição no Brasil. No entanto, com exceção do sul do Brasil e norte da Argentina, todos os demais registros são baseados em apenas um espécime de cada localidade, indicando que essa espécie não é comun nessas regiões. Em vista disso, a identificação de $C$. aseada em trabalhos com populações de percevejos-verdes do DF (por ex. Fernandes \& Bao 2000; Suji et al. 2002) necessita ser revisada. Hospedeiras conhecidas incluem diversas plantas cultivadas, incluíndo soja (Tabela II); nenhuma informação sobre o tipo de associação com elas é conhecida. Tamanho dos adultos: $12-14 \mathrm{~mm}$

Distribuição: Brasil (PA nov. reg., MT nov. reg., DF, PR nov. reg., RS), Argentina.

\section{Chinavia bipunctula $($ Stål)}

(Fig. 6)

Espécie de coloração geral verde, face dorsal com pequenas máculas amareladas; margens do corpo com estreita faixa de coloração amarelada, cicatrizes do pronoto com $2+2$ manchas negras, ângulos basais do escutelo imaculados, manchas da margem posterior do conexivo estendendo-se pelo menos até a metade da largura deste; espiráculos castanhos, calo junto aos espiráculos presente. Distingue-se de C. herbida pelo tamanho maior, presença das máculas amareladas na face dorsal, manchas das cicatrizes do pronoto presentes, pernas ferrugíneas e presença de calo junto aos espiráculos; diferencia-se de $C$. herbida e $C$. impicticornis pelos espiráculos negros. Até a realização deste trabalho, esta espécie era conhecida apenas pelo lectótipo fêmea e paralectótipo macho, esse último sem o pigóforo. Rolston (1983) ampliou a distribuição de C. bipunctula (como Acrosternum bipunctulum) para Equador e Peru, no entanto o material identificado por ele foi estudado para este trabalho e permitiu concluir que não tratava-se efetivamente de $C$. bipunctula (ver comentários na diagnose de C. impicticornis). Silva et al. (1968) citam C. bipunctula (como Nezara bipunctula) sobre algodão, arroz e soja; Grazia (1977) examinou os espécimes citados por Silva et al. (1968) e concluiu que tratavam-se de $C$. impicticornis (citada como Acrosternum impicticornis). Planta 
hospedeira desconhecida. Tamanho dos adultos: 12-13mm. Distribuição: Brasil (BA).

\section{Chinavia brasicola (Rolston)}

(Fig. 7)

Espécie de coloração dorsal verde a verde-escura, com margens das jugas, pronoto, terço basal do hemiélitro e conexivo de coloração vermelha a vermelho-alaranjada; cicatrizes do pronoto e ângulos basais do escutelo com 1+1 manchas negras, espiráculos negros, calo junto aos espiráculos presente. Distingue-se de C. apicicornis (Spinola, 1837) e $C$. australe (Rolston, 1983), espécies com distribuição apenas no Chile e Argentina, pelo maior tamanho, pela coloração dos espiráculos e presença das manchas nas cicatrizes do pronoto e ângulos póstero-laterais do conexivo. Posturas e ninfas foram coletadas sobre Dennstaedtia globulifera (Tabela II) em mata de araucária no RS. Deste grupo de pentatomídeos, apenas $C$. marginata tem uma pteridófita registrada como plantahospedeira (Perez-Gelabert \& Thomas 2005). Tamanho dos adultos: $12-15 \mathrm{~mm}$.

Distribuição: Brasil (SP nov. reg., SC, RS nov. reg.).

\section{Chinavia callosa (Rolston)}

(Fig. 8)

Coloração geral do corpo verde, cicatrizes do pronoto e base do escutelo imaculados; mancha da margem posterior do conexivo se estendendo pelo menos até metade da largura desta; pontuação da face dorsal do corpo profunda, conferindo aspecto rugoso. Única espécie de Chinavia com a mancha do conexivo estendendo-se ao longo da margem posterior e que apresenta o espinho abdominal ultrapassando as metacoxas. Não tem registro para o Brasil, planta hospedeira desconhecida. Tamanho dos adultos: 11-12mm

Distribuição: Bolívia, Paraguai, Argentina.

\section{Chinavia cearensis Schwertner \& Grazia}

Coloração dorsal verde-esmeralda; bordo do pronoto, do hemiélitro e conexivo de coloração creme, semelhante ao padrão de coloração de C. nigritarsis; diferencia-se desta pelas margens das jugas de coloração vermelho-alaranjada, faixa de coloração creme nas margens do pronoto, escutelo e hemiélitro menos conspícua, antenas e pernas não manchadas de negro e membranas do hemiélitro transparentes; os machos possuem ainda a parte apical dos fêmures e parte basal das tíbias de coloração avermelhada. A forma de $C$. gravis discutida em Schwertner \& Grazia (2006b) na diagnose de C. cearensis, trata-se efetivamente de $C$. nigritarsis, que é revalidada neste trabalho. Planta hospedeira desconhecida. Holótipo ilustrado em Schwertner \& Grazia (2006b). Tamanho dos adultos: 14$15 \mathrm{~mm}$.

Distribuição: Brasil (CE).
Chinavia dallasi (Distant)

(Fig. 9)

Coloração geral do corpo verde a verde-clara, margens do corpo com ampla faixa de coloração vermelha a vermelhoalaranjada, cicatrizes do pronoto com $2+2$ machas negras e ângulos basais do escutelo com 1+1 manchas negras; manchas da margem posterior do conexivo amplas, estendendo-se pelo menos até a metade da largura deste. Distingue-se de $C$. impicticornis pelos espiráculos negros e presença de calo junto aos espiráculos. Conhecida apenas pelo lectótipo fêmea; Rolston (1983) registrou C. dallasi (como Acrosternum dallasi) para o Brasil. No entanto, o estudo comparado do lectótipo dessa espécie com o material estudado por Rolston (1983) permitiu concluir que os espécimes coletados no Brasil não se tratavam de $C$. dallasi; esta espécie, portanto, não tem registro confirmado para o Brasil. Planta hospedeira desconhecida. Tamanho dos adultos: $12-14 \mathrm{~mm}$.

Distribuição: Colômbia.

\section{Chinavia difficilis (Stål)}

(Figs. 10)

Coloração geral do corpo verde a verde-clara; cicatrizes do pronoto, ângulos basais do escutelo e conexivo sem manchas negras. Distingue-se de $C$. obstinata pelo espinho abdominal mais curto, não atingindo as mesocoxas, e espiráculos escuros; distingue-se de C. napaea pelas antenas de coloração verde e gonocoxitos 8 planos. Eventualmente, algum espécime de $C$. napaea pode ser confundido com $C$. difficilis, mas as características diagnósticas aqui apresentadas permitem a identificação dessas duas espécies. Planta hospedeira desconhecida. Tamanho dos adultos: $12-15 \mathrm{~mm}$

Distribuição: Brasil (RJ, SP nov. reg.).

\section{Chinavia erythrocnemis (Berg)}

(Fig. 11)

Coloração da face dorsal verde-clara a verde-escura, margens das jugas com ampla faixa de coloração vermelha, cicatrizes do pronoto escuras, ângulos basais do escutelo com 1+1 manchas negras; manchas do conexivo presentes nas margens anterior e posterior, estendendo-se pelo menos até a metade da largura destes; conexivo de coloração amarelada, espiráculos claros, suturas e pseudosuturas abdominais enegrecidas. Eventualmente alguns espécimes de $C$. erythrocnemis podem apresentar as suturas e pseudosuturas não manchadas, mas os espiráculos são sempre claros. Espécie facilmente reconhecida pelo padrão de coloração geral do corpo. No Brasil, C. erythrocnemis tem ampla distribuição apenas no RS, com menor número de coletas nos demais estados. Imaturos descritos em Matesco et al. (2006), sendo a única espécie estudada de Chinavia que oviposita massas com número médio de 12 ovos (demais espécies conhecidas ovipositam massas de ovos com número médio de 14 ou múltiplo de 7; Schwertner et al. 2002; Matesco et al. 2007). 

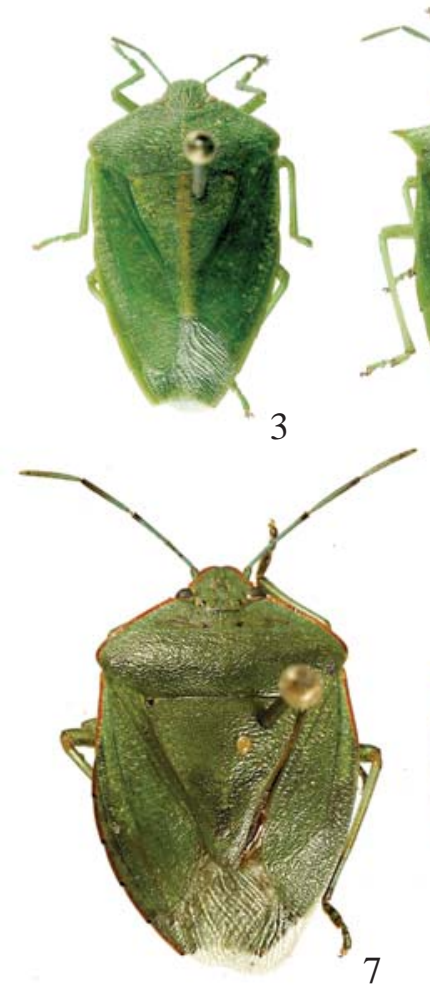

7

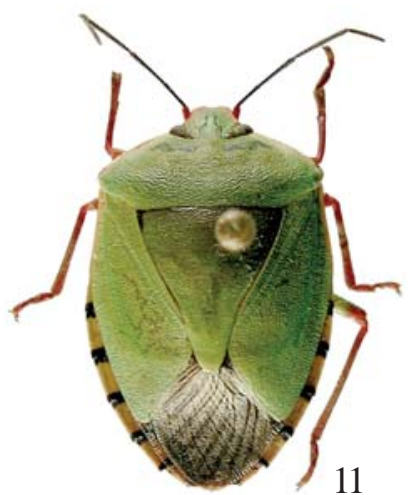

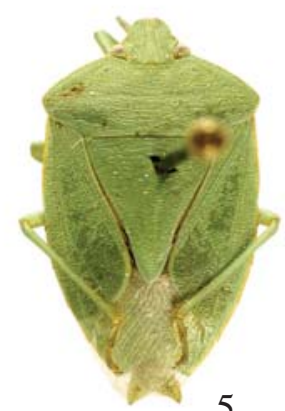

5

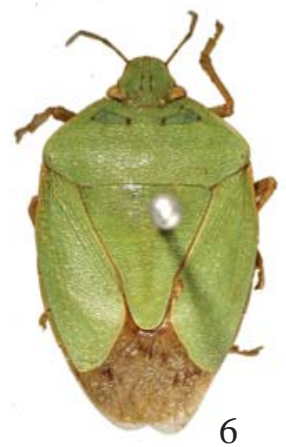

$\mid \begin{aligned} & \Xi \\ & \square\end{aligned}$
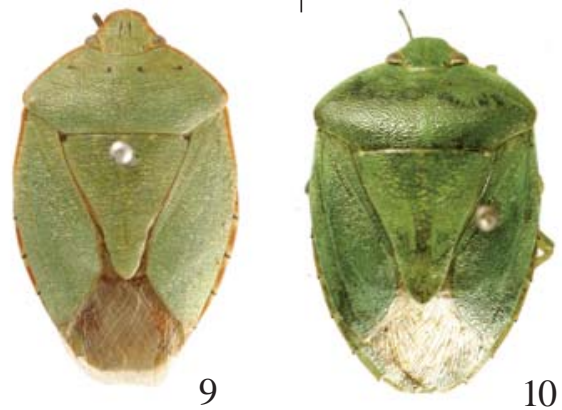
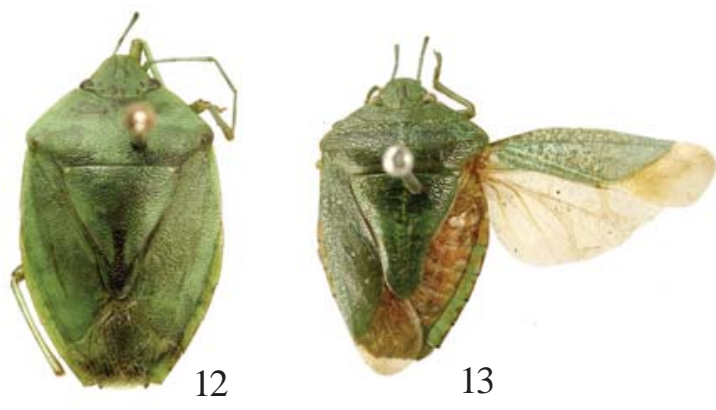

13

Figs. 3-13. 3, Chinavia abnormis; 4, C. armigera; 5, C. aseada (holótipo ơ); 6, C. bipunctula (lectótipo o ); 7, C. brasicola (holótipo ơ); 8, C. callosa (holótipo); ơ; 9, C. dallasi (lectótipo +); 10, C. dificillis (holótipo + ); 11, C. erythrocnemis; 12, C. esmeralda (holótipo ơ); 13, C. fuscopunctata (holótipo o ).

Registrada em soja no RS (Tabela II). Tamanho dos adultos: $11-14 \mathrm{~mm}$.

Distribuição: Brasil (MT, SP, PR, SC, RS), Paraguai, Argentina.

\section{Chinavia esmeralda (Rolston)}

(Fig. 12)

Coloração geral do corpo verde-esmeralda; cicatrizes do pronoto, ângulos basais do escutelo e conexivo sem manchas negras. Distingue-se das demais espécies de Chinavia com espinho abdominal longo pelas margens laterais das jugas apenas levemente côncavas adiante dos olhos, dando um aspecto mais amplo à cabeça. Espécie endêmica do sudeste e sul do Brasil, em MG é registrada apenas no sul do estado. Planta hospedeira desconhecida. Tamanho dos adultos: 11$13 \mathrm{~mm}$.

$$
\text { Distribuição: Brasil (MG, RJ, SC). }
$$

\section{Chinavia fuscopunctata (Breddin)} (fig. 13)

Coloração geral do corpo verde; cicatrizes do pronoto e ângulos basais do escutelo sem manchas negras; conexivo com margens de coloração avermelhada; manchas junto aos ângulos póstero-laterais do conexivo presentes; espiráculos 
verdes ou castanho-claros. Distingue-se de $C$. schuhi e $C$. simplicis pelo tamanho menor, pontuação da face dorsal mais marcada, presença das manchas do conexivo, espinho abdominal cônico e margem posterior dos gonocoxitos sinuosas e convergentes no ápice. Eventualmente, algum espécime mal conservado de $C$. impicticornis poderá ser identificado pelos passos da chave como C. fuscopunctata, mas a forma do corpo, padrão de coloração, forma da cabeça, profundidade das pontuções e forma dos gonocoxitos 8 dessas duas espécies é bastante distinta. Espécie conhecida apenas do holótipo fêmea, sem registro de planta hospedeira. Tamanho da fêmea: $10,5 \mathrm{~mm}$.

Dsitribuição: Brasil (ES).

\section{Chinavia geniculata (Dallas)}

(Fig. 14)

Coloração do corpo verde-clara a verde-oliva; cicatrizes do pronoto, ângulos basais do escutelo e conexivo sem manchas negras; membrana do hemiélitro enfuscada; conexivo de coloração amarelada. Distingue-se das demais espécies pelo tamanho maior, coloração do corpo, espinho abdominal não atingindo as metacoxas e apenas ápice do fêmur manchado de negro. Com registro somente no RJ, planta hospedeira desconhecida. Tamanho dos adultos: 14-17mm.

Distribuição: Brasil (RJ).

\section{Chinavia gravis (Walker)}

(Fig. 15)

Coloração geral do corpo verde-escura, com ampla faixa longitudinal mediana no escutelo, margens das jugas, pronoto, terço basal do hemiélitro e conexivo de coloração creme; pernas manchadas de negro. Espécie com distribuição restrita à região amazônica, facilmente reconhecida pelo padrão de coloração. O holótipo de Nezara gentilis Breddin, 1903, sinônimo júnior de C. gravis (ver Rolston, 1983), é ilustrado (Fig. 15). Planta hospedeira desconhecida. Tamanho dos adultos: $12-14 \mathrm{~mm}$.

Distribuição: Colômbia, Brasil (RO, AM, MT), Peru.

\section{Chinavia herbida (Stål)}

(Fig. 16)

Coloração geral do corpo verde a verde-clara; cicatrizes do pronoto e ângulos basais do escutelo sem manchas negras; mancha do conexivo se estendendo pelo menos até a metade da largura deste. Distingue-se de C. bipunctula pelo tamanho menor, face dorsal de coloração uniforme, pernas completamente verdes e conexivo de coloração amarelada. Diferencia-se de C. impicticornis pelos ângulos basais do escutelo imaculados, espinho abdominal atingindo as metacoxas e pela presença de uma faixa longitudinal mediana de coloração amarela sobre o escutelo (Grazia, 1979). Rolston (1983) cita esta espécie para o Brasil (como Acrosternum herbidum), mas o material estudado neste trabalho não confirma essa distribuição, sendo a espécie restrita à região central da Argentina. Associada a hospedeiras de diferentes famílias, todas plantas cultivadas (Tabela II). Tamanho dos adultos: $10-12 \mathrm{~mm}$.

Distribuição: Argentina.

\section{Chinavia immaculata (Frey-da-Silva \& Grazia)}

(Fig. 17)

Coloração geral do corpo verde a verde-clara, com ampla faixa de coloração vermelha a vermelho-alaranjada nas margens das jugas, pronoto, ápice do escutelo, terço basal do hemiélitro e conexivo; cicatrizes do pronoto, ângulos basais do escutelo e conexivo sem manchas negras. Distingue-se das demais espécies de Chinavia pela coloração avermelhada da base do fêmur, base e ápice da tíbia e tarsos. Espécie com ocorrência apenas na região norte e central do Brasil, sem registro de planta hospedeira. Tamanho dos adultos: 9-11 mm.

Distribuição: Brasil (PA, MT, MG).

\section{Chinavia impicticornis (Stål)}

(Fig. 18)

Espécie de coloração geral do corpo verde, com margens das jugas, pronoto, terço basal do hemiélitro e conexivo amarelados a alaranjados; manchas das cicatrizes do pronoto podem estar presentes, ângulos basais do escutelo com 1+1 manchas negras; manchas do conexivo junto às margens posteriores estendendo-se pelo menos até a metade da largura do segmento; espiráculos verdes. Distingue-se de $C$. bipunctula pela presença das manchas nos ângulos basais do escutelo e de $C$. dallasi pelos espiráculos claros. Espécie com ampla distribuição na América do Sul; em geral, espécimes do norte do Brasil apresentam coloração mais escura e tamanho menor. Eventualmente, alguns espécimes de $C$. impicticornis podem apresentar as manchas dos ângulos basais do escutelo ausentes ou as manchas dos conexivos mais curtas, sendo identificada a partir dos passos da chave como C. herbida ou C. fuscopunctata. Grazia (1979) apresentou uma diagnose comparada entre $C$. herbida e $C$. impicticornis (citadas como Acrosternum herbidum e A. impicticornis respectivamente), e considerou Nezara vicina Berg, 1892 sinônimo júnior de $C$. impicticornis. É registrada em plantas hospedeiras de diversas famílias (geralmente citada como Acrosternum impicticorne), muitas delas cultivadas (Tabela II), considerada praga secundária de soja e outras culturas no Brasil (Panizzi et al. 2000). A citação de $C$. bipunctula (como Nezara bipunctula) em algodão, arroz, e soja em MG (Silva et al. 1968) trata-se de C. impicticornis (Grazia 1977, citada como Acrosternum impicticornis). Ninfas descritas em Grazia et al. (1982), discutidas em Panizzi \& Grazia (2001) e Schwertner et al. (2002). A bionomia dessa espécie em diferentes plantas cultivadas foi estudada por Schwertner (dados não publicados), que confirmou o hábito polífago dessa espécie. As ilustrações de Acrosternum hilare em Gallo et al. (2002) correspondem efetivamente a C. impicticornis (ver p. 315 discussão sobre Chinavia hilaris). Tamanho dos adultos: 11-16mm. 


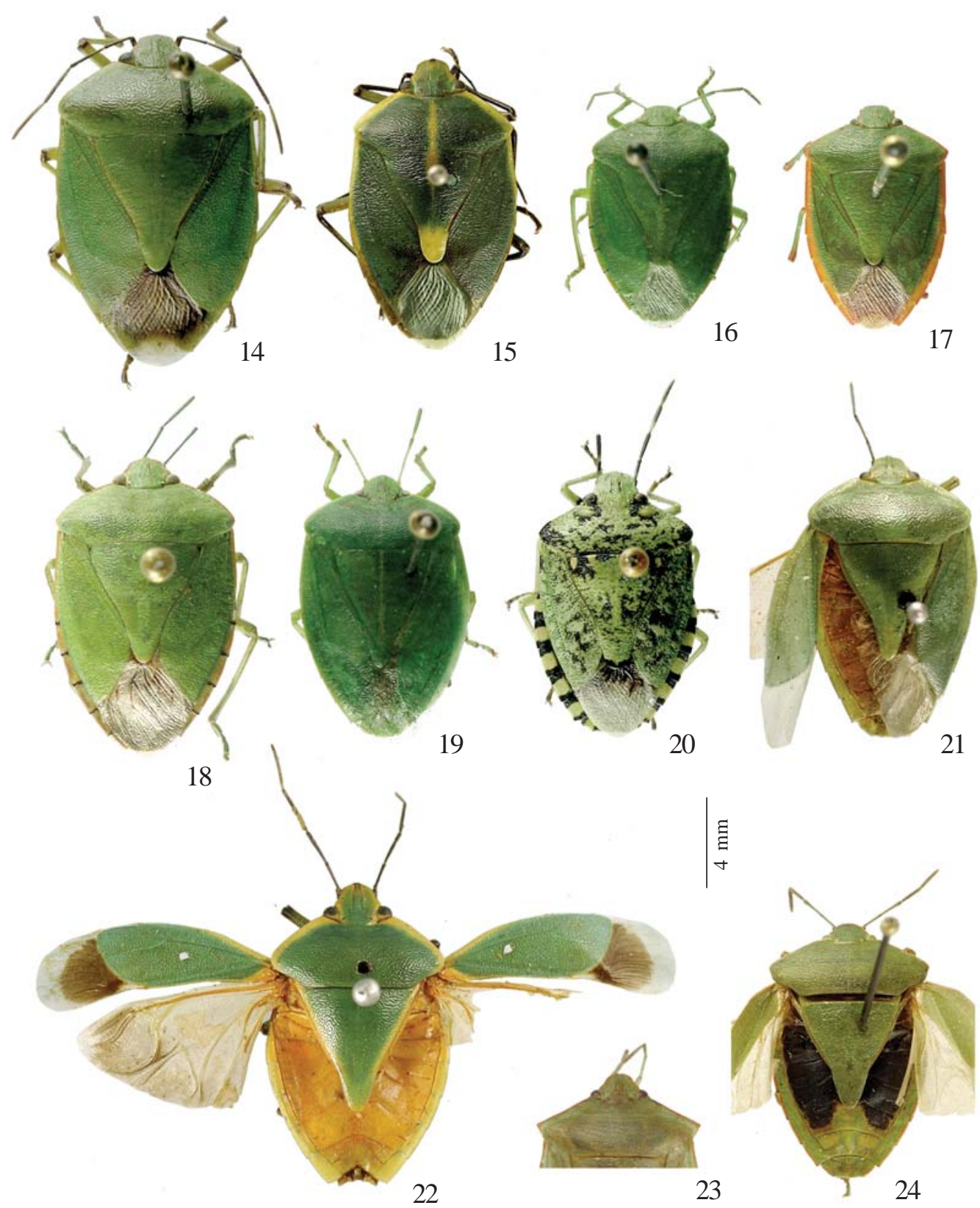

Figs. 14-24. 14, Chinavia geniculata; 15, Nezara gentilis (holótipo o ) [= C. gravis]; 16, C. herbida; 17, C. immaculata (holótipo ơ); 18, C. impicticornis; 19, C. longicorialis; 20, C. musiva; 21, C. napaea (holótipo ơ); 22, C. nigritarsis (lectótipo ơ); 23 e 24, C. nigridorsata (23, cabeça e pronoto do holótipo ơ de A. bellum syn. nov.; 24, holótipo o de C. nigrodorsata).

Distribuição: Venezuela, Suriname, Colômbia, Equador, Bolívia, Brasil (AM, PA, MA, MT, GO, DF, BA, MG, RJ, SP, PR, SC, RS), Peru, Paraguai, Argentina.

\section{Chinavia longicorialis (Breddin)}

(Fig. 19)

Espécie de coloração verde, com faixa longitudinal mediana e margens do corpo de coloração amarelada; rostro de coloração vermelha. Calos junto aos espiráculos presentes, espinho abdominal ultrapassando as metacoxas. Espécie bastante coletada no RS, facilmente identificada pelo espinho abdominal longo, ultrapassando as metacoxas, presença de calo amarelo junto ao espiráculo e cório do hemiélitro ultrapassando a metade do conexivo VII. Coletada em pêssego no Uruguai; outras possíveis plantas-hospedeiras são registradas pela primeira vez nesse trabalho (Tabela II). Tamanho dos adultos: $12-13 \mathrm{~mm}$.

Distribuição: Brasil (SP nov. reg., PR nov. reg., RS), Argentina, Uruguai. 


\section{Chinavia musiva (Berg)}

(Fig. 20)

Espécie de coloração geral do corpo verde-clara, com máculas negras em toda a face dorsal; manchas no conexivo, nas margens anterior e posterior, amplas, calos junto aos espiráculos bem desenvolvidos. Facilmente reconhecida pelo padrão de coloração do corpo; no Brasil, onde nunca havia sido registrada, ocorre no RS, apresentando ampla distribuição em toda a metade sul do estado. Registrada sobre plantas de três famílias diferentes (Tabela II). Tamanho dos adultos: 10$13 \mathrm{~mm}$

Distribuição: Brasil (RS nov. reg.), Argentina, Uruguai.

\section{Chinavia napaea (Stål)}

(Figs. 21)

Coloração geral do corpo verde-clara a verde-escura; cicatrizes do pronoto, ângulos basais do escutelo e conexivo sem manchas negras; distingue-se de C. obstinata pelo corpo mais alongado (comprimento maior que 1,5 vezes a largura), espinho abdominal mais curto e espiráculos escuros, e de $C$. difficilis pelas jugas mais estreitas e gonocoxitos fortemente convexos. Espécie conhecida apenas de fêmeas. O holótipo possui as antenas enegrecidas, característica utilizada por Rolston (1983) em sua chave de identificação, e mantida neste trabalho, para diferenciar $C$. difficilis das demais espécies de Chinavia com espinho abdominal longo, que ultrapassa as metacoxas. O estado de conservação dos demais espécimes analisados não permitiu confirmar esta característica. Planta hospedeira desconhecida. Tamanho dos adultos: 13-14mm.

Distribuição: Brasil (RJ).

\section{Chinavia nigritarsis (Stål) reval.}

(Fig. 22)

Coloração dorsal verde-esmeralda, bordos do pronoto e hemiélitro e todo o conexivo de coloração creme; semelhante ao padrão de coloração de $C$. cearensis, mas com as faixas de coloração creme mais conspícuas. Diferencia-se de $C$. cearensis pelo ápice da cabeça e margens das jugas de coloração creme, antenas, pernas e tarsos manchados de negro e membranas do hemiélitro enfuscadas. Foi considerada sinônimo júnior de $C$. gravis por Rolston (1983). A forma de $C$. gravis discutida em Schwertner \& Grazia (2006b) na diagnose de $C$. cearensis, trata-se efetivamente de $C$. nigritarsis, que tem seu status revalidado neste trabalho. Planta hospedeira desconhecida. Tamanho dos adultos: 13-15mm.

Distribuição: Brasil (AM).

\section{Chinavia nigrodorsata (Breddin)}

(Figs. 23 e 24)

Acrosternum (Chinavia) bellum Rolston, 1983 Syn. nov.

Espécie de coloração geral do corpo verde, com margens das jugas, pronoto, terço basal do hemiélitro e conexivo de coloração avermelhada; cicatrizes do pronoto e ângulos basais do escutelo sem manchas negras, manchas do conexivo junto aos âgulos póstero-laterais presentes, espiráculos escuros e calo junto aos espiráculos presente. Distingue-se de C. ubica pelo desenvolvimento dos ângulos umerais, geralmente em espinho em $C$. nigrodorsata; distingue-se de $C$. armigera pelas jugas mais estreitas e padrão de coloração das margens do corpo. Esta espécie era registrada no sul do Brasil como $C$. armigera (citada como Acrosternum armigerum) e, após a descrição de Rolston (1983), como C. bella (Rolston 1983, Vecchio et al. 1988, Panizzii et al. 2000, citada como Acrosternum bellum). Com base nos espécimes-tipo examinados para este trabalho, Acrosternum bellum (Fig. 23) é considerada sinônimo júnior de $C$. nigrodorsata. Espécie comum no sul do Brasil, Argentina e Uruguai, tem registros em plantas hospedeiras de diferentes famílias, incluindo várias plantas cultivadas (Tabela II). No material estudado, um espécime fêmea tem registro para o estado da PB, e provavelmete representa uma introdução isolada dessa espécie nessa região do Brasil. Ninfas descritas por Vecchio et al. (1988); biologia discutida por Avalos \& La Porta (1996). Tamanho dos adultos: 11-13 mm.

Distribuição: Brasil (PB nov. reg., MG, SP, PR, RS), Argentina, Uruguai.

\section{Chinavia nigropicta (Breddin)}

(Fig. 25)

Coloração geral do corpo verde-ferrugínea, cicatrizes do pronoto enegrecidas, escutelo com ampla macha negra basal, conexivos imaculados. Conhecida apenas do holótipo fêmea, facilmente identificada pelo padrão de coloração. Planta hospedeira desconhecida. Tamanho da fêmea: $14 \mathrm{~mm}$.

Distribuição: Brasil (AM).

\section{Chinavia obstinata (Stål)}

(Figs. 26 e 27)

Acrosternum (Chinavia) panizzii Frey-da-Silva \& Grazia, 2001 Syn. nov.

Coloração geral do corpo verde-clara a verde-escura; cicatrizes do pronoto, ângulos basais do escutelo imaculados, conexivo imaculado (Fig. 26) ou com amplas manchas negras junto aos ângulos póstero-laterais (Fig. 27). Espinho abdominal ultrapassando as mesocoxas. Distingue-se de $C$. difficilis pelo corpo mais ovalado (comprimento menor que 1,5 vezes a largura), espinho abdominal mais longo e espiráculos claros. Eventualmente, algum espécime de $C$. napaea pode ser confundido com C. obstinata, que se distingue daquela pelas jugas mais estreitas e gonocoxitos levemente convexos. Neste trabalho, o estudo do holótipo de Acrosternum panizzii permitiu estabelecer esta espécie como sinônimo júnior de $C$. obstinata; a única diferença evidente entre estas duas formas são as manchas junto aos ângulos póstero-laterais do 

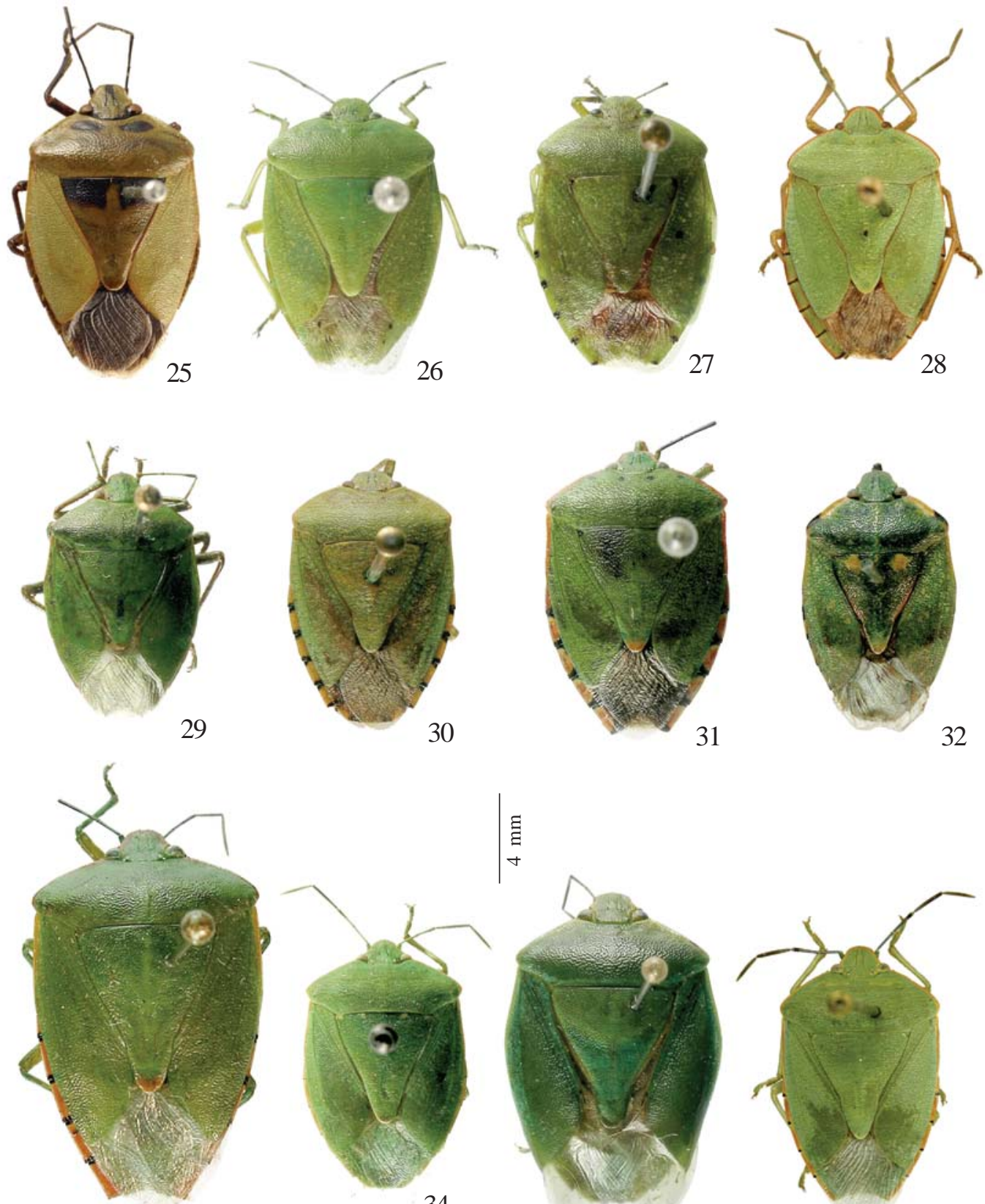

30

31

33
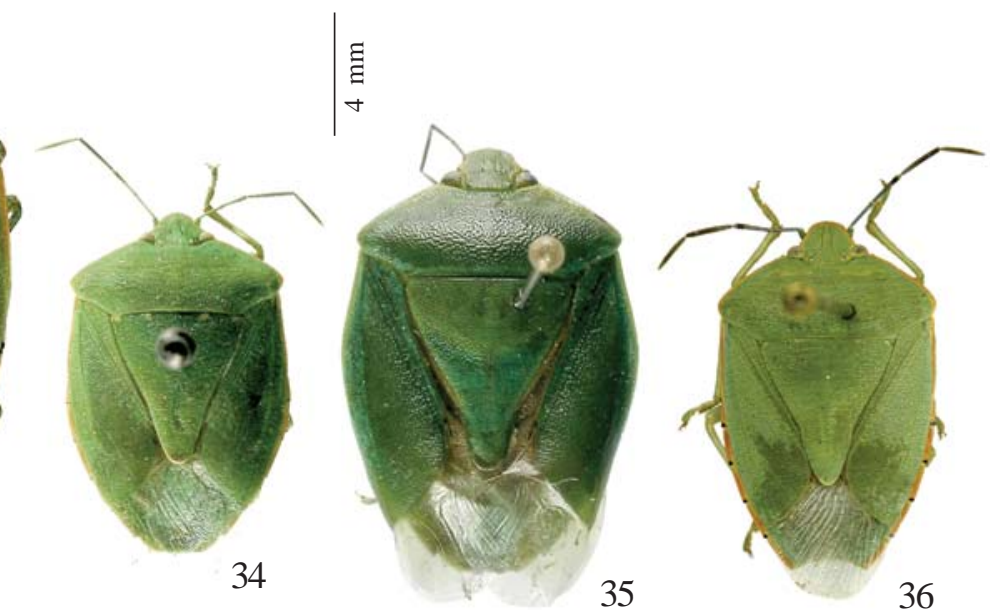

Figs. 25-36. 25, Chinavia nigropicta (holótipo o); 26, C. obstinata; 27, C. obstinata (parátipo o de A. panizzii syn.nov.); 28, C. pengue (holótipo $\left.\sigma^{\top}\right) ; 29$, C. plaummani, (holótipo $\sigma^{\top}$ ); 30, C. pontagrossensis (holótipo + ); 31, C. rideri (parátipo ơ); 32, C. rogenhoferi, 33, C. runaspis; 34, C. simplicis; 35, C. tuiucauna (holótipo $\sigma^{7}$ ); 36, C. ubica (holótipo $\sigma^{7}$ ).

conexivo, que parece ser uma variação populacional dentro da espécie e ocorre, até o momento, apenas em indivíduos coletados no PR. Espécie registrada na faixa oriental das regiões sudeste e sul do Brasil, geralmente associada a plantas de maracujá; no PR foi coletada sobre soja (Tabela II). Descrição dos imaturos, incluindo aspectos da biologia, descritos e discutidos em Matesco et al. (2003). Tamanho dos adultos: $11-15 \mathrm{~mm}$.

Distribuição: Brasil (MG, RJ, SP, PR, SC, RS).

\section{Chinavia pengue (Rolston)}

(Fig. 28)

Coloração geral do corpo verde a verde-clara; margens das jugas, pronoto, terço basal do hemiélitro e conexivo de coloração vermelha a vermelho-alaranjada; presença de pequenas máculas amareladas na face dorsal do corpo; manchas junto às margens posteriores do conexivo atingindo pelo menos a metade da largura deste. Distingue-se de $C$. impicticornis pelos ângulos basais do escutelo imaculados e 
espiráculos negros; distingue-se de C. bipunctula, C. herbida e $C$. rufitibia pela coloração das margens do corpo. Espécie bastante comum no sul do Brasil e norte da Argentina, registrada em diversas plantas cultivadas no RS (Tabela II). Imaturos e biologia descritos e discutidos em Matesco et al. (2007). Tamanho dos adultos: 11-13 mm.

Distribuição: Brasil (PR, SC, RS), Paraguai, Argentina.

\section{Chinavia plaumanni (Rolston)}

(Fig. 29)

Coloração geral do corpo verde a verde-escura; margens do corpo com estreita borda amarelada; cicatrizes do pronoto e ângulos basais do escutelo sem manchas negras, mancha junto aos ângulos póstero-laterais do conexivo atingindo pelo menos a metade da largura deste; espiráculos verdes. Distingue-se das demais espécies de Chinavia pela mancha do conexivo estreita e espinho abdominal inconspícuo, formando um tubérculo. Espécie pouco comum, coletada na região amazônica, mas sem registro para o Brasil. Planta hospedeira desconhecida. Tamanho dos adultos: 11-12mm.

Distribuição: Colômbia, Equador.

\section{Chinavia pontagrossensis (Frey-da-Silva \& Grazia)} (Fig. 30)

Coloração geral do corpo verde-clara a verde-escura, estreita faixa nas margens das jugas e conexivo de coloração amarelada a alaranjada; pronoto com pelo menos $1+1$ manchas junto às cicatrizes do pronoto, escutelo sem manchas junto aos ângulos póstero-laterais; manchas das margens anterior e posterior do conexivo ultrapassando a metade da largura deste; espiráculos verdes, não acompanhados por calo. Distinguese de $C$. runaspis pela pontuação da face dorsal mais profunda e espinho abdominal mais curto. Espécie com registro apenas no Brasil. Encontrada sobre soja no Paraná (Tabela II). Tamanho dos adultos: $12-13 \mathrm{~mm}$.

Distribuição: Brasil (SP nov. reg., PR).

\section{Chinavia rideri (Frey-da-Silva \& Grazia)}

(Fig. 31)

Coloração geral do corpo verde a verde-escura, com margens das jugas, pronoto, ápice do escutelo, terço basal do hemiélitro e conexivo com ampla faixa vermelha a vermelhoalaranjada; cicatrizes do pronoto com $2+2$ manchas negras; manchas do conexivo presentes nas margens anterior e posterior, estendendo-se pelo menos até a metade da largura deste. Eventualmente algum espécime de $C$. rideri pode apresentar as suturas e pseudosuturas mais escuras, no entanto os espiráculos são sempre escuros. Distingue-se facilmente de C. erythrocnemis, assim como das demais espécies do gênero, pelo padrão de coloração. Espécie comum na região central do Brasil, registrada sobre soja (Tabela II). Tamanho dos adultos: $12-14 \mathrm{~mm}$.

Distribuição: Brasil (AM, MT, GO, DF, MG).

\section{Chinavia rogenhoferi (Stål)}

(Fig. 32)

Coloração geral do corpo verde; pontuação da face dorsal verde-escura; margens das jugas avermelhadas; margens do pronoto com dois terços basais de coloração creme a alaranjada, terço apical do pronoto e ângulos umerais negros; cicatrizes do pronoto e ângulos basais do escutelo imaculados, com 1+1 manchas de coloração creme junto à margem anterior do escutelo; manchas junto aos bordos anterior e posterior do conexivo ulltrapassando a metade da largura deste. Distingue-se das demais espécies de Chinavia pelo padrão de coloração. Espécie conhecida apenas para a região sudeste do Brasil, sem registro de planta hospedeira. Tamanho dos adultos: $12-13 \mathrm{~mm}$.

Distribuição: Brasil (RJ).

\section{Chinavia rufitibia Schwertner \& Grazia}

Coloração geral do corpo verde; margens da cabeça, pronoto, hemiélitro e conexivo de coloração amarela a amareloalaranjada; manchas da margem posterior do conexivo se estendendo pelo menos até a metade da largura deste. Diferencia-se de C. impicticornis e C. herbida pelas tíbias de coloração avermelhada e ângulos basais do escutelo sem manchas negras. Conhecida apenas da região sul do Brasil, registrada sobre soja (Tabela II). Holótipo ilustrado em Schwertner \& Grazia (2006b). Tamanho dos adultos: 9-12 mm.

Distribuição: Brasil (PR).

\section{Chinavia runaspis (Dallas)}

(Fig. 33)

Coloração geral do corpo verde-clara a verde-escura, com ampla faixa vermelha a vermelho-alaranjada nas margens das jugas, pronoto, terço basal do hemiélitro e conexivo; cicatrizes do pronoto e ângulos basais do escutelo sem manchas negras; manchas nas margens anterior e posterior do conexivo amplas, ultrapassando a metade da largura destes; espiráculos verdes. Distingue-se de C. pontagrossensis pelo tamanho maior, corpo mais alongado (comprimento maior que 1,5 vezes a largura) e pontuação da face dorsal mais rasa. Espécie bastante comum, juntamente com C. impicticornis e C. ubica, apresenta distribuição ampla, praticamente em toda América do Sul. Espécimes da região amazônica têm coloração mais escura. Abundante em coletas com armadilha de luz, principalmente no norte do Brasil. Apenas duas plantas hospedeiras são conhecidas, ambas de famílias pouco comuns para as espécies do gênero (Tabela II). Tamanho dos adultos: 15-19 mm.

Distribuição: Venezuela, Suriname, Colômbia, Brasil (AM, PA, MG, RJ, SP, SC, RS), Peru, Paraguai, Argentina.

\section{Chinavia schuhi Schwertner \& Grazia}

Coloração geral do corpo verde; bordos da cabeça, pronoto, hemiélitro e conexivo vermelhos; pontuação da face 
dorsal do pronoto, escutelo e hemiélitros verde-escura; cicatrizes do pronoto e ângulos basais do escutelo imaculados; rostro ultrapassando as metacoxas. Diferencia-se de C. aseada e C. ubica pela coloração do espiráculo castanho-clara, ângulos umerais agudos e bordos posteriores dos gonocoxitos 8 levemente convexos. Diferencia-se de C. nigrodorsata e $C$. simplicis pela ausência de calo amarelo junto aos espiráculos. Única espécie de Chinavia com rostro longo, ultrapassando as metacoxas. Espécie de distribuição amazônica, sem registro de planta hospedeira. Holótipo ilustrado em Schwertner \& Grazia (2006b). Tamanho dos adultos: $12-15 \mathrm{~mm}$.

Distribuição: Brasil (AM), Peru.

\section{Chinavia sebastiaoi Schwertner \& Grazia}

Coloração geral do corpo verde-clara, margens da cabeça, pronoto, hemiélitro e conexivo com estreita faixa de coloração amarelada; cicatrizes do pronoto e ângulos basais do escutelo imaculados; membrana do hemiélitro transparente. Pontuação da face dorsal rasa; espinho abdominal ultrapassando as metacoxas. Distingue-se de C. esmeralda pelas jugas fortemente côncavas adiante dos olhos e pontuação mais rasa e menos densa; de C. napaea e C. obstinata pelo tamanho maior e gonocoxitos 8 planos; distingue-se de $C$. difficilis pelos espiráculos de coloração verde. Espécie com poucos dados de coleta, no Brasil é registrada apenas na Serra da Bodoquena (MS). Eventualmente, em algum espécime cujo espinho abdominal seja interpretado como não ultrapasando as metacoxas, a chave levará ao passo juntamente com $C$. cearensis e $C$. tuiucauna; distingue-se destas pelo padrão de coloração e pelas margens do pronoto convexas. Planta hospedeira desconhecida. Holótipo ilustrado em Schwertner \& Grazia (2006b). Tamanho dos adultos: 14-16 mm.

Distribuição: Brasil (MS), Bolívia, Paraguai.

\section{Chinavia simplicis (Rolston)}

(Fig. 34)

Espécie de coloração geral verde, com as margens do corpo, bordos da cabeça, do pronoto, do hemiélitro e do conexivo vermelhos a vermelho-claros; cicatrizes do pronoto e ângulos basais do escutelo imaculados, manchas junto aos ângulos póstero-laterais do conexivo podem estar presentes. Distingue-se de $C$. aseada, C. nigrodorsata e C. ubica pelo espiráculo ferrugíneo, mais claro. As características de Chinavia monticola (Rolston, 1983), conhecida apenas do Peru, coincidem com os passos da chave que levam à identificação de C. simplicis, descrita originalmente do Paraguai (Rolston, 1983). Planta hospedeira deconhecida. Tamanho dos adultos: 11-13 mm.

Distribuição: Brasil (MT nov. reg.), Paraguai.

\section{Chinavia tuiucauna Schwertner \& Grazia} (Fig. 35)

Coloração geral do corpo verde-oliva; margens da cabeça e do escutelo com estreita faixa difusa de coloração amarelada a creme; cicatrizes do pronoto, ângulos basais do pronoto e conexivo não machados de negro; membrana do hemiélitro transparente. Distingue-se de C. sebastiaoi pelo espinho mais curto e de $C$. cearensis pelo padrão de coloração (ver diagnose dessas duas espécies). Espécie conhecida apenas do holótipo fêmea, coletada em cacaueiro (Tabela II). Tamanho da fêmea: $15,5 \mathrm{~mm}$.

Distribuição: Brasil (BA).

\section{Chinavia ubica (Rolston)}

(Fig. 36)

Espécie de coloração geral verde, com as margens do corpo, bordos da cabeça, do pronoto, do hemiélitro e do conexivo vermelhos a vermelho-alaranjados; cicatrizes do pronoto e ângulos basais do escutelo imaculados, conexivo com manchas junto aos ângulos póstero-laterais presentes. Distingue-se de $C$. simplicis pelo espiráculo negro, de $C$. aseada pelas manchas do conexivo e de C. nigrodorsata pelos ângulos umerais arredondados. Possui padrão único do pigóforo. Espécie com ampla distribuição na América do Sul, excluindo apenas Paraguai, Argentina e Uruguai. Muito comum em praticamente todas as coleções estudadas, no entanto possui relativamente poucas plantas-hospedeiras conhecidas, a maioria delas cultivadas (Tabela II). Panizzi (2002) cita C. ubica (como Acrosternum ubicum) como parte do complexo de percevejos na cultura da soja no sul do MA. Estudos sobre a biologia dessa espécie em diferentes plantas cultivadas (Schwertner, dados não publicados) indicaram um maior potencial reprodutivo quando comparada com outras espécies do gênero (Matesco et al. 2007). Ninfas apresentam formas claras e escuras a partir do terceiro instar, sendo que a proporção entre as diferentes formas está relacionada ao alimento utilizado (Schwertner et al. 2002). Tamanho dos adultos: $11-14 \mathrm{~mm}$.

Distribuição: República Dominicana, Bahamas, Ilhas Granadas, Panamá, Suriname, Guiana, Venezuela, Colômbia, Brasil (AP, PA, MA, RN, CE, PE, MT, GO, DF, BA, MG, ES, RJ, SP, SC), Equador, Bolívia.

\section{Chinavia vanduzeei Schwertner \& Grazia}

Coloração geral do corpo verde-oliva, com o ápice da cabeça, contorno do corpo e ápice do escutelo e bordo posterior do hemiélitro de coloração creme. Antenas, rostro e tíbia manchados de negro; membranas do hemiélitro enfuscadas. O padrão de coloração desta espécie é único dentro do gênero. Distribuição amazônica, sem registro de plantas hospedeiras. Holótipo ilustrado em Schwertner \& Grazia (2006b). Tamanho dos adultos: 11-14 mm.

Distribuição: Brasil (AM, PA, MA), Peru.

Agradecimentos. Aos curadores das coleções citadas, pelo empréstimo do material estudado, em especial a Aline Barcellos (MCNZ), Domique Pluot-Sigwalt (MNHN), Luiz Costa (MNRJ), Randall T. Schuh 
(AMNH), †Sebastião Oliveira (FIOC) e Thomas Henry (NMNH) por receberem o primeiro autor pessoalmente nas respectivas instituições. Randall T. Schuh (AMNH) foi fundamental para obtenção de grande parte do material-tipo examinado, além de ter oportunizado e supervisionado todo o período de estágio sanduíche em que o primeiro autor permaneceu no AMNH. A CAPES e ao CNPq pelas bolsas concedidas aos autores; além disso, muitos dos dados inéditos aqui apresentados só foram possíveis devido ao auxílio do CNPq a projetos do DZ-UFRGS cujo objetivo é o estudo da biodiversidade de insetos do RS. À Aline Barcellos, Ernesto Prado, Fernando Rocha, Jorge L. C. Bernardes, Letícia Schmidt e Viviana C. Matesco por testarem diferentes versões da chave pictórica e pelas sugestões apresentadas. A Caroline Greve, Aline Barcellos e um revisor anônimo pela leitura crítica do manuscrito e correções sugeridas.

\section{REFERÊNCIAS}

Avalos, D. S. \& N. C. La Porta. 1996. Biología de Acrosternum bellum Rolston, 1983 (Hemiptera, Pentatomidae). Agriscientia 13: 2530 .

Bertels, A. 1962. Insetos-hóspedes de solanáceas. Iheringia, Série Zoologia 25: 1-11

Bertels, A. \& E. Ferreira. 1973. Levantamento atualizado dos insetos que vivem nas culturas de campo no Rio Grande do Sul. Universidade Católica Pelotas, Série Publicações Científicas 1: 1-17.

Carvalho, R. S.; M. Borges \& F. G. V. Schmidt. 1995. Ocorrência de Acrosternum aseadum Rolston (Heteroptera: Pentatomidae: Pentatomini) na cultura da soja no Brasil central. Anais da Sociedade Entomológica do Brasil 24: 415-417.

Coll, O. R. \& E. S. Saini. 1992. Insectos y acaros perjudiciales al cultivo de la yerba mate en la Republica Argentina. Publicacion $\mathrm{n}^{\circ} 1$, Instituto Nacional de Tecnologia Agropecuária, E.E.A. Montecarlo, Missiones. 48 p.

Costa, E. C. \& D. Link. 1974. Incidência de percevejos em soja. Revista do Centro de Ciências Rurais 4: 397-400.

Costa Lima, A. M. 1940. Insetos do Brasil, $2^{\circ}$ tomo, Hemípteros. Rio de Janeiro. Imprensa Nacional. $351 \mathrm{p}$.

Eger, J. E. 1988. A new species of Acrosternum Fieber, subgenus Chinavia Orian, from Ecuador (Heteroptera: Pentatomidae: Pentatomini). Florida Entomologist 71: 120-124.

Fernandes, A. D. \& S. N. Bao. Ultrastructural and cytochemical studies of the spermatozoa of Acrosternum aseadum (Hemiptera: Pentatomidae). Biocell 25: 173-177.

Frey-da-Silva, A. \& J. Grazia. 2001. Descrição de quatro novas espécies do subgênero Chinavia Orian com chave para identificação das espécies do gênero Acrosternum Fieber (Heteroptera, Pentatomidae, Pentatomini). Iheringia, Série Zoologia 90: 107-126.

Gallo, D.; N. Nakano; S. Silveira Neto; R. P. L. Carvalho; G. C. de Baptista; E. Berti Filho; J. R. P. Parra; R. A. Zucchi; S. B. Alves; J. D. Vendramim; L. C. Marchini; J. R. S. Lopes \& C. Omoto. 2002. Entomologia Agrícola. Piracicaba. FEALQ. 920 p.

Grazia, J. 1977. Revisão dos pentatomíneos citados no "Quarto catálogo dos insetos que vivem nas plantas do Brasil" (HemípteraPentatomidae-Pentatomini). Dusenia 10: 161-174.

Grazia, J. 1979. Sobre os tipos de Acrosternum impicticorne (Stal, 1872), Acrosternum herbidus (Stal, 1859) e Acrosternum vicina (Berg, 1892) (Heteroptera; Pentatomidae). Anais da Sociedade Entomológica do Brasil 8: 233-238.

Grazia, J.; M. C. D. Vecchio \& R. Hildebrand. 1982. Estudo das ninfas de pentatomídeos (Heteroptera) que vivem sobre soja [Glycine max (L.) Merrill]: IV - Acrosternum impicticorne (Stal, 1872). Anais da Sociedade Entomológica do Brasil 11: 261-268.

Grazia, J.; C. F. Schwertner \& A. Ferrari. 2006. Description of five new species of Chinavia Orian (Hemiptera, Pentatomidae, Pentatominae) from western and northwestern South America, p. 423-434 . In: W. Rabitsch (ed.). Hug the bug - For love of true bugs. Festschrift zum 70 Geburtstag von.Ernst Heiss, Denisia
19. Biologiezentrum der Oberösterreichische Landeesmuseen, Linz. $1184 \mathrm{p}$.

Link, D. 1979. Entomofauna da lentilha. I - Percevejos Pentatomidae (Hemiptera). Revista do Centro de Ciências Rurais 9: 379 385.

Link, D. \& J. Grazia. 1987. Pentatomídeos da região central do Rio Grande do Sul (Heteroptera). Anais da Sociedade Entomológica do Brasil 16: 115-129.

Link, D.; V. Estefanel; O. S. Santos; M. C. Mezzomo \& L. E. V. Abreu. 1973. Influência do ataque de pentatomídeos nas características agronômicas do grão de soja, Glycine $\max$ (L.) Merrill. Anais da Sociedade Entomológica do Brasil 2: 59-65.

Lopes, O. J.; D. Link \& I. V. Basso. 1974. Pentatomídeos de Santa Maria - lista preliminar de plantas hospedeiras. Revista do Centro de Ciências Rurais 4: 317-322.

Magrini, E. A.; S. Silveira Neto; P. S. M. Botelho \& S. G. Negrim. 1996. Ocorrência de percevejos no município de Pirassununga-SP, associados com a fenologia da soja. Revista de Agricultura Piracicaba 71: 187-195.

Matesco, V. C.; N. D. F. Fortes \& J. Grazia. 2003. Imaturos de pentatomídeos (Hemiptera, Heteroptera): morfologia e biologia de Acrosternum obstinatum. Iheringia, série Zoologica 93: 8188 .

Matesco, V. C.; C. F. Schwertner \& J. Grazia. 2006. Descrição dos estágios imaturos de Chinavia erythrocnemis (Berg) (Hemiptera, Pentatomidae). Neotropical Entomology 35: 483-488.

Matesco, V. C.; C. F. Schwertner \& J. Grazia. 2007. Descrição dos estágios imaturos e biologia de Chinavia pengue (Hemiptera, Pentatomidae). Revista Brasileira de Entomologia 51: 93 100.

Mitchell, P. 2006. Polyphagy in true bugs: a case study of Leptoglossus phyllopus (L.) (Hemiptera, Heteroptera, Coreidae), p. 1117-1134. In: W. Rabitsch (ed.). Hug the bug - For love of true bugs. Festschrift zum 70 Geburtstag von Ernst Heiss, Denisia 19. Biologiezentrum der Oberösterreichische Landeesmuseen. Linz. $1184 \mathrm{p}$.

Panizzi, A. R. 2002. Stink bugs on soybean in northeastern Brazil and a new record on the southern sreen stink bug, Nezara viridula (L.) (Heteroptera: Pentatomidae). Neotropical Entomology 31: 331332.

Panizzi, A. R. \& J. Grazia. 2001. Stink bugs (Heteroptera, Pentatomidae) and an unique host plant in the Brazilian subtropics. Iheringia, Série Zoologia 90: 21-35.

Panizzi, A. R; J. E. McPherson; D. G. James; M. Javahery \& R. M. McPherson. 2000. Stink bugs (Pentatomidae), p. 421-474. In: C. W. Schaefer \& A. R. Panizzi (eds.), Heteroptera of economic importance. Boca Raton. CRC Press. 828 p.

Panizzi, A. R. \& J. G. Smith. 1976. Ocorrência de Pentatomidae em soja no Paraná durante 1973/74. Biológico 42: 173-176.

Pennington, M. S. 1919. Notas sobre las espécies argentinas del género Nezara A. \& S. Physis, Buenos Aires 4: 527-529.

Perez-Gelabert, D. E. \& D. B. Thomas. 2005. Stink bugs (Heteroptera: Pentatomidae) of the island of Hispaniola, with seven new species from the Dominican Republic. Boletin de la Sociedad Entomológica Aragonesa 37: 319-352.

Pirán, A. 1968. Hemiptera neotropica XI. Revista de la Sociedad Entomológica Argentina 30: 17-25

Quintanilla, R. H.; A. E. Margheritis \& H. F. Rizzo. 1976. Catalogo de hemipteros hallados en la Provincia de Corrientes (Argentina). Revista de la Sociedad Entomologica Argentina 35: 115133.

Quintanilla, R. H.; H. F. Rizzo \& A. S. de Núñez. 1981. Catalogo preliminar de Hemipteros hallados en la provincia Misiones (Argentina). Revista de la Facultad de Agronomía 2: 145-161.

Rolston, L. H. 1983. A revision of the genus Acrosternum Fieber, subgenus Chinavia Orian in the Western Hemisphere (Hemiptera, Pentatomidae, Pentatomini). Journal of the New York Entomological Society 91: 97-176.

Santos, J. H. \& M. A. W. Quinderé. 1988. Distribuição, importância e manejo das pragas do caupi no Brasil, p. 605-658. In: Araújo, J. P. 
P. \& E. E. Watt. (eds.). O caupi no Brasil. Brasília. IITA/EMBRAPA. $722 \mathrm{p}$.

Suji, E. R; M. L. M Costa; C. S. S. Pires; S. Colazza \& M. Borges. 2002. Inter and intra-guild interactions in egg parasitoid species of the soybean stink bug complex. Pesquisa Agropecuária Brasileira 37: $1541-1549$.

Schwertner, C. F. \& J. Grazia. 2002. Nomenclator entomologicus 43: Acrosternum spp. em soja no Brasil. Informativo da Sociedade Entomológica do Brasil 27: 3.

Schwertner, C. F. \& J. Grazia. 2006a. Nomenclator entomologicus 58: O gênero Chinavia Orian nas Américas. Informativo da Sociedade Entomológica do Brasil 31: 3 .

Schwertner, C. F. \& J. Grazia. 2006b. Descrição de seis novas espécies de Chinavia Orian (Hemiptera, Pentatomidae, Pentatominae) da América do Sul. Iheringia, série Zoologia 97: 237-348

Schwertner, C. F.; G. S. A. Albuquerque \& J. Grazia. 2002. Descrição dos estágios imaturos de Acrosternum (Chinavia) ubicum Rolston (Heteroptera, Pentatomidae) e efeito do alimento no tamanho e coloração das ninfas. Neotropical Entomology 31: 571-579.

Silva A. G. d'A.; C. R. Gonçalves; D. M. Galvão; A. J. L. Gonçalves; J. Gomes; M. N. Silva \& L. Simoni. 1968. Quarto catálogo dos insetos que vivem nas plantas do Brasil, seus parasitos e predadores, parte dois, tomo I. Rio de Janeiro. Ministério da Agricultura. $622 \mathrm{p}$

Souza, V. C. \& H. Lorenzi 2005. Botânica Sistemática: guia ilustrado para identificação das famílias de Angiospermas da flora brasileira, baseado em APG II. Nova Odessa. Instituto Plantarum. 640 pp.

Vecchio, M. C. D.; J. Grazia \& R. Hildebrand. 1988. Estudo dos imaturos de pentatomídeos (Heteroptera) que vivem sobre soja [Glycine $\max ($ L.) Merrill]: V - Acrosternum bellum Rolston, 1983 com a descrição da genitália da fêmea. Anais da Sociedade Entomológica do Brasil 17: 467-482.

Zucchi, R. A.; S. Silveira Neto \& O. Nakano. 1993. Guia de identificação de pragas agrícolas. Piracicaba. FEALQ. 139 p.

Recebido em 03/05/2007; aceito em 06/11/2007 